OPEN ACCESS

Edited by:

Maren Müller,

University of Barcelona, Spain

Reviewed by:

Woei-Jiun Guo,

National Cheng Kung University,

Taiwan

Hao Peng,

Washington State University, USA

*Correspondence:

Agata Daszkowska-Golec agata.daszkowska@us.edu.pl

Specialty section:

This article was submitted to

Plant Physiology,

a section of the journal

Frontiers in Plant Science

Received: 30 September 2016 Accepted: 29 November 2016 Published: 16 December 2016

Citation:

Skubacz A, Daszkowska-Golec A and Szarejko I (2016) The Role and Regulation of $A B / 5$

(ABA-Insensitive 5) in Plant Development, Abiotic Stress Responses and Phytohormone Crosstalk. Front. Plant Sci. 7:1884.

doi: $10.3389 /$ fpls.2016.01884

\section{The Role and Regulation of ABI5 (ABA-Insensitive 5) in Plant Development, Abiotic Stress Responses and Phytohormone Crosstalk}

\author{
Anna Skubacz, Agata Daszkowska-Golec* and Iwona Szarejko \\ Department of Genetics, Faculty of Biology and Environmental Protection, University of Silesia, Katowice, Poland
}

$\mathrm{ABA}$ Insensitive $5(\mathrm{ABI})$ is a basic leucine zipper transcription factor that plays a key role in the regulation of seed germination and early seedling growth in the presence of $\mathrm{ABA}$ and abiotic stresses. $\mathrm{ABI} 5$ functions in the core ABA signaling, which is composed of PYR/PYL/RCAR receptors, PP2C phosphatases and SnRK2 kinases, through the regulation of the expression of genes that contain the ABSCISIC ACID RESPONSE ELEMENT (ABRE) motif within their promoter region. The regulated targets include stress adaptation genes, e.g., LEA proteins. However, the expression and activation of $A B / 5$ is not only dependent on the core $A B A$ signaling. Many transcription factors such as ABI3, ABI4, MYB7 and WRKYs play either a positive or a negative role in the regulation of $A B / 5$ expression. Additionally, the stability and activity of $\mathrm{ABI} 5$ are also regulated by other proteins through post-translational modifications such as phosphorylation, ubiquitination, sumoylation and S-nitrosylation. Moreover, ABI5 also acts as an ABA and other phytohormone signaling integrator. Components of auxin, cytokinin, gibberellic acid, jasmonate and brassinosteroid signaling and metabolism pathways were shown to take part in $A B / 5$ regulation and/or to be regulated by $A B I 5$. Monocot orthologs of $A t A B / 5$ have been identified. Although their roles in the molecular and physiological adaptations during abiotic stress have been elucidated, knowledge about their detailed action still remains elusive. Here, we describe the recent advances in understanding the action of $\mathrm{ABI} 5$ in early developmental processes and the adaptation of plants to unfavorable environmental conditions. We also focus on ABI5 relation to other phytohormones in the abiotic stress response of plants.

\footnotetext{
Keywords: ABI5, abiotic stress response, phytohormone crosstalk, abscisic acid, brassinosteroids, gibberellin acid, jasmonates, posttranslational modification
}

\section{INTRODUCTION}

Abiotic stresses, such as drought, salinity or heat, have become a major threat for crop plant survival and yield. Full understanding of the mechanisms ensuring plant adaptation to stress can assist in obtaining tolerant varieties. ABA, which is the major stress phytohormone, takes part in a plant's adaptation to stress through regulation of physiological processes such as the 
biosynthesis of osmolytes and the detoxification of ROS (Reactive Oxygen Species); (reviewed by Roychoudhury et al., 2013; Mehrotra et al., 2014; Yoshida et al., 2014; Munemasa et al., 2015; Jones, 2016; Sah et al., 2016). Generally, ABA is considered to be a shoot and root growth inhibitor that acts to save water and energy under stress. However, in some cases $\mathrm{ABA}$ promotes root growth and enables the root system to access water in deeper soil layers (Sharp et al., 2004; Skirycz and Inzé, 2010; Zhao et al., 2014). ABA also prevents turgor loss under conditions of reduced water availability. One of the earliest protective processes that are observed in stressed plants is stomatal closure. The endogenous ABA level is precisely controlled by biosynthesis and the catabolism pathways. ABA biosynthesis is a multistage process that is dependent on many enzymes including NCED (CAROTENOID CLEAVAGE DIOXYGENASE). ABA catabolism requires ABA8'hydroxylase activity and results in the creation of phaseic acid (reviewed by Mehrotra et al., 2014; Sah et al., 2016). The perception of an ABA signal is mainly dependent on the core ABA signaling, which includes the action of PYR/PYL/RCAR (PYRABACTIN RESISTANCE PROTEINS/PYR-LIKE PROTEINS/REGULATORY COMPONENTS OF ABA RECEPTOR) receptors, PPC (PHOSPHATASE 2C) phosphatases and SnRK2 (SNF1-RELATED PROTEIN KINASE 2) kinases. Finally, AREB/ABF (ABSCISIC ACID RESPONSIVE ELEMENTS-BINDING FACTOR) transcription factors bind to ABRE (ABA RESPONSIVE ELEMENT) elements and regulate the expression of stress responsive genes (reviewed by Nakashima and YamaguchiShinozaki, 2013; Yoshida et al., 2014; Daszkowska-Golec, 2016). ABA-dependent transcription factors are primarily members of large families such as bZIP (BASIC LEUCINE ZIPPER) (Banerjee and Roychoudhury, 2015), MYB (MYELOBLASTOSIS) (Golldack et al., 2011), WRKY (WRKY DNA-BINDING PROTEIN) (Chen L. et al., 2012) or AP2 (APETALA 2) (Golldack et al., 2011). ABI5 (ABA INSENSITIVE 5), which is a bZIP transcription factor, functions in the core ABA signaling.

The effect of mutation in $A B I 5$ gene was firstly described by Finkelstein's (1994) group. Arabidopsis insertional mutant abi5 was characterized as ABA insensitive in comparison to the wild type during seed germination. The mutation was mapped on 2 chromosome (Finkelstein, 1994). Transcriptomic analysis of abi5 mutant indicated the lower level of expression of stress responsive genes. It suggested the role of $A B I 5$ in abiotic stress response (Finkelstein and Lynch, 2000). Further $A B I 5$-related expression analysis confirmed its role in drought and salt adaption during seedling development (Finkelstein and Lynch, 2000; Lopez-Molina et al., 2001; Nakamura et al., 2001). The ABI5-regulated inhibition of seed germination and early seedling growth protects against plant development in adverse conditions. However, the ABI5 function is not only restricted to embryo tissues and its role was also described in the vegetative stage of development (Brocard et al., 2002; Kong et al., 2013). The target genes of ABI5 enable further adaptations to abiotic stresses.

In this review, we present the current understanding of the way ABI5 functions as (1) a regulator of abiotic stress responses and (2) an integrator of ABA crosstalk with other phytohormones. The results that are described primarily refer to research on Arabidopsis thaliana as the model plant.

\section{SEED GERMINATION UNDER THE CONTROL OF ABA IN THE PRESENCE OF ABIOTIC STRESS}

The process of seed germination is a critical stage in the plant life cycle and therefore plants have evolved precise mechanisms for its regulation (Debeaujon et al., 2000; Manz et al., 2005; Fait et al., 2006; Finch-Savage and Leubner-Metzger, 2006; Nonogaki et al., 2010; Rajjou et al., 2012).

Gibberellic acid (GA) and ABA are the main phytohormones that participate in the regulation of the seed germination process (reviewed by Jacobsen et al., 2002; Daszkowska-Golec, 2011). GA is well known as a positive regulator of seed germination. An environment that is favorable for seed germination leads to the activation of the GA biosynthesis genes - GA3OX1 (GIBBERELLIN 3-OXIDASE 1) and GA3OX2, which results in a higher content of the active GA pool (Ogawa et al., 2003; Mitchum et al., 2006). Next, GA responsive genes encoding key regulators and enzymes for germination are activated. The increase of GA during seed germination is associated with a decrease of ABA. The low ABA level is caused by the activity of CYP707A2 (CYTOCHROME P450) encoding ABA8' hydroxylase and is responsible for ABA catabolism in seeds (Kushiro et al., 2004; Miransari and Smith, 2014). On the contrary, seed dormancy, which prevents germination under unfavorable conditions, is connected with a high ABA and low GA content (Okamoto et al., 2006; Liu et al., 2014). To summarize, the complex ABA and GA interplay enables seed germination at the appropriate moment.

Sometimes, seeds start to germinate prior to the occurrence of abiotic stress. The inhibition of germination and prevention of germinating embryo from dryness is conducted through the ABA-dependent pathway described above. However, plants develop a special subtype of $\mathrm{ABA}$ action, which requires the action of seed specific, ABA-dependent transcription factors such as $\mathrm{ABI} 3, \mathrm{ABI} 4$, and $\mathrm{ABI}$. Mutations in these $A B I$ loci lead to an ABA, salt and osmotic stress insensitivity during seed germination (Finkelstein, 1994; Carles et al., 2002; Nambara et al., 2002). ABI3 has a B3 domain and activates genes via an $\mathrm{Ry} / \mathrm{Sph}$, seed-specific enhancer element that is present in the promoter sequences. Its function is mainly attributed to the maintenance of embryogenesis and seed dormancy. The loss of this function results in damaged seed development (Finkelstein and Somerville, 1990). ABI3 induces the expression of MIR159 encoding the negative regulator of MYB33 and MYB101. Both of these act as positive components of ABA signaling. This indicates that $\mathrm{ABI} 3$ is responsible for the negative feedback regulation of the ABA cascade in germinating seeds that are under abiotic stress (Reyes and Chua, 2007). ABI4, a transcription factor with an AP2 domain, also functions during seed germination under abiotic stress. The target genes of ABI4 have CE1 (COUPLING ELEMENT 1) in their promoter regions. ABI4 was shown to 
play a significant role in the ABA-dependent inhibition of lateral root development (De Smet et al., 2003; Shkolnik-Inbar and Bar-Zvi, 2010). Additionally, it has a negative influence on the expression of photosynthesis-related genes and mediates the plant response to glucose (Acevedo-Hernández et al., 2005; Bossi et al., 2009). ABI4 is also assumed to participate in the regulation of $\mathrm{ABA}$ signaling through the activation of the MIR159b expression and it also targets mature miR159 - MYB33 and MYB101 (Daszkowska-Golec et al., 2013). ABI3 and ABI4 were observed to act together with $\mathrm{ABI} 5$ in the regulation of abiotic stress responses (Nakamura et al., 2001; Reeves et al., 2011).

\section{ABI5 - THE CRUCIAL REGULATOR OF SEED GERMINATION PROCESS}

In germinating seeds and young seedlings, ABA signal perception is also governed by the ABI5 bZIP transcription factor. ABI5 shows a high homology to AREBs and also functions in a similar manner (Finkelstein and Lynch, 2000; Kim, 2006; Yoshida et al., 2010). Its expression is activated by drought and salt stress during seed germination within a short developmental window, which occurs between 48 and $60 \mathrm{~h}$ after stratification. Therefore, ABI5 activity causes the inhibition of seed germination or early seedling growth. A correlation was shown between ABA sensitivity, the expression of $A B I 5$ and the re-establishment of desiccation tolerance (Maia et al., 2014). Growth inhibition of the embryo and root at a later stage of development ensures more water retention and thus drought tolerance (Lopez-Molina et al., 2001; Brocard et al., 2002; Maia et al., 2014). Under stress, SnRK2.2, SnRK2.3 and SnRK2.6 phosphorylate the ABI5 trans-activation domain in vegetative tissues. The phosphorylation of ABI5 changes its conformation and enables its further interactions with other proteins (Nakamura et al., 2001). The first targets of ABI5 that were identified were the genes encoding LEA proteins, EM1 (EARLY METHIONINE-LABELED 1), EM6 and LEAD34 (Finkelstein and Lynch, 2000). Additionally, in a Yeast OneHybrid assay, ABI5 was shown to bind directly with the ABRE sequence in the EM6 promoter (Nakamura et al., 2001; Carles et al., 2002).

Many ABI5 target genes are associated with the germination process, e.g., PGIP1 (POLYGALACTURONASE INHIBITING PROTEIN 1) and PGIP2 genes (Kanai et al., 2010) (Figure 1). The induction of their ABI5-mediated expression leads to the inhibition of the activity of polygalacturanases, which results in the retardation of seed coat rupture and thus germination. In these processes, $A B I 5$ is under the negative regulation of $P E D 3$ (PEROXISOME DEFECTIVE 3), which encodes the ATP-binding cassette transporter that is associated with fatty acid $\beta$ oxidation. Thus, ABI5 acts as a crucial regulator of germination through its involvement in physiological and the biochemical aspects of this process (Kanai et al., 2010) (Figure 1).

\section{FURTHER SEEDLING DEVELOPMENT IS NOT POSSIBLE WITHOUT ABI5 FUNCTIONING}

Some reports indicate that the ABI5 function is not only restricted to germination and post-germinative growth, but also includes the vegetative tissues. $A B I 5$ expression has been observed in root tips, nodes and leaf veins at the seedling stage, while in older plants, its activity has been shown at the edges of leaves and in flowers. Additionally, many target genes are regulated by ABI5 at the later stages of plant development. ABA-induced

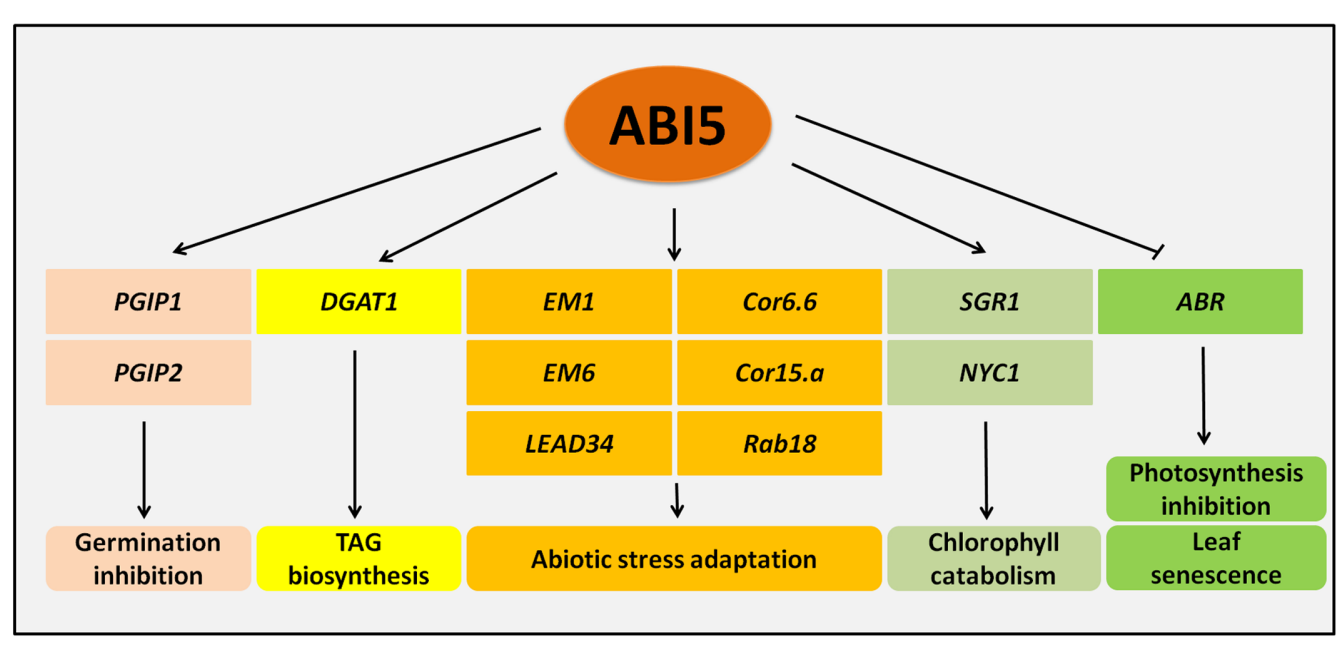

FIGURE 1 | Genes regulated by ABI5. ABI5 (ABA INSENSITIVE5) activates the expression of PGIP (POLYGALACTURONASE INHIBITING PROTEIN) genes encoding polygalacturonase inhibitors, which in turn inhibits seed germination. Another ABI5 target, DGAT1 (DIACYLGLYCEROL ACYLTRANSFERASE 1), participates in TAG (TRIACYLGLYCEROL) biosynthesis and ensures adaptation to stress in seedlings. A group of LEA (LATE EMBRYOGENESIS ABUNDANT) genes is also positively regulated by $A B \mid 5$ under abiotic stress. Additionally, $A B \mid 5$ negatively influences the chlorophyll content, photosynthesis efficiency and leaf senescence via promotion of SGR1 (STAYGREEN1), NYC1 (NON-YELLOW COLORING 1) and repression of ABR (ABA RESPONSIVE PROTEIN). 
expression of $E M 1$ was decreased in the vegetative tissues of an abi5 mutant and ABI5 overexpression in 2-week-old plants was observed to have some positive impact on the expression of the ABA-responsive genes Cor6.6, Cor15a and Rab18 (Finkelstein and Lynch, 2000; Brocard et al., 2002). In 7-day-old seedlings, ABI5 regulates the expression of DGAT1 (DIACYLGLYCEROL ACYLTRANSFERASE 1) in the presence of salt and osmotic stress in an ABA-dependent way. DGAT1 encodes a key enzyme in TAG (TRIACYLGLYCEROL) biosynthesis, which is accumulated in stressed plants (Kong et al., 2013). The involvement of ABI5 in the regulation photosynthesis is another example of its function in vegetative tissues. The genes that are responsible for chlorophyll catabolism, SGR1 (STAYGREEN1) and NYC1 (NONYELLOW COLORING 1), contain an ABRE element in their promoters and are positively regulated by ABI5 together with another transcription factor, EEL (ENHANCED EM LEVEL) (Sakuraba et al., 2014) (Figure 1). These results indicate that ABI5 acts as a negative regulator of photosynthesis through the activation of chlorophyll degradation.

Lateral roots development is also regulated by ABI5. Similar to $\mathrm{ABI} 4, \mathrm{ABI} 5$ has an influence on the lateral root length. An abi5 mutant showed a weakened response to ABA- and nitratemediated lateral root growth inhibition (Signora et al., 2001). Additionally, ABA induces $A B I 5$ expression in the lateral root tips. These results indicate that ABI5 acts as a negative regulator of lateral root development in the presence of stress (Brocard et al., 2002; De Smet et al., 2003; Shkolnik-Inbar and Bar-Zvi, 2010).

ABI5 and ABI4 not only act together during lateral root formation. The ABI5-regulated gene, DGAT1 encoding the TAG (TRIACYLGLYCEROL) biosynthesis enzyme is also activated by ABI4 (Kong et al., 2013). Furthermore, many genes encoding LEA, dehydrins and oleosins were shown to be regulated by both ABI4 and ABI5. Additionally, ABA pathway-related transcription factors and regulators were identified in the group of genes/proteins that are commonly regulated by ABI4 and ABI5. Among them, negative ABA regulators such as AHG1 (ABA-HYPERSENSITIVE GERMINATION 1) were also detected. Thus, both ABI transcription factors are simultaneously a part of a positive and negative feedback loop in the ABAsignaling. Furthermore, ABI5-specific targets seem to demand other co-regulators compared to ABI4-regulated genes (Reeves et al., 2011).

\section{THE ROLE OF ABI5 IN SENESCENCE PROCESS}

Recently, ABI5 was shown to take a part in a dark-induced leaf senescence process. It negatively and directly regulates $A B R$ (ABA RESPONSIVE PROTEIN) expression in the darkness. $A B R$, a gene encoding a LEA protein, is a stress responsive gene that is associated with leaf rescue from the senescence process. The probable mechanism was shown to be related to the photosynthesis proteins. Thus, ABI5 plays a positive role in leaf senescence through its negative impact on the photosynthesis process (Su et al., 2016) (Figure 1).

\section{ABI5 IS REGULATED BY MULTIPLE TRANSCRIPTION FACTORS AND OTHER PROTEIN REGULATORS}

Regulation of the $A B I 5$ expression is complex and is mediated through many regulators. ABI5 expression is under the control of multiple transcription factors and proteins that belong to other functional groups (Figure 2).

\section{Positive Regulators of ABI5}

$\mathrm{ABI} 3$ and ABI4 transcription factors are positive regulators of the expression of $A B I 5$ in the ABA-dependent pathway during both seed germination and early seedling development (Finkelstein and Lynch, 2000; Söderman et al., 2000; Lopez-Molina et al., 2002; Bossi et al., 2009). Furthermore, ABI5 activates its own expression by binding to the ABI5 promoter (Brocard et al., 2002) (Figure 2A). However, in the presence of abiotic stress the negative feedback loop in ABA signaling ensures the balance in

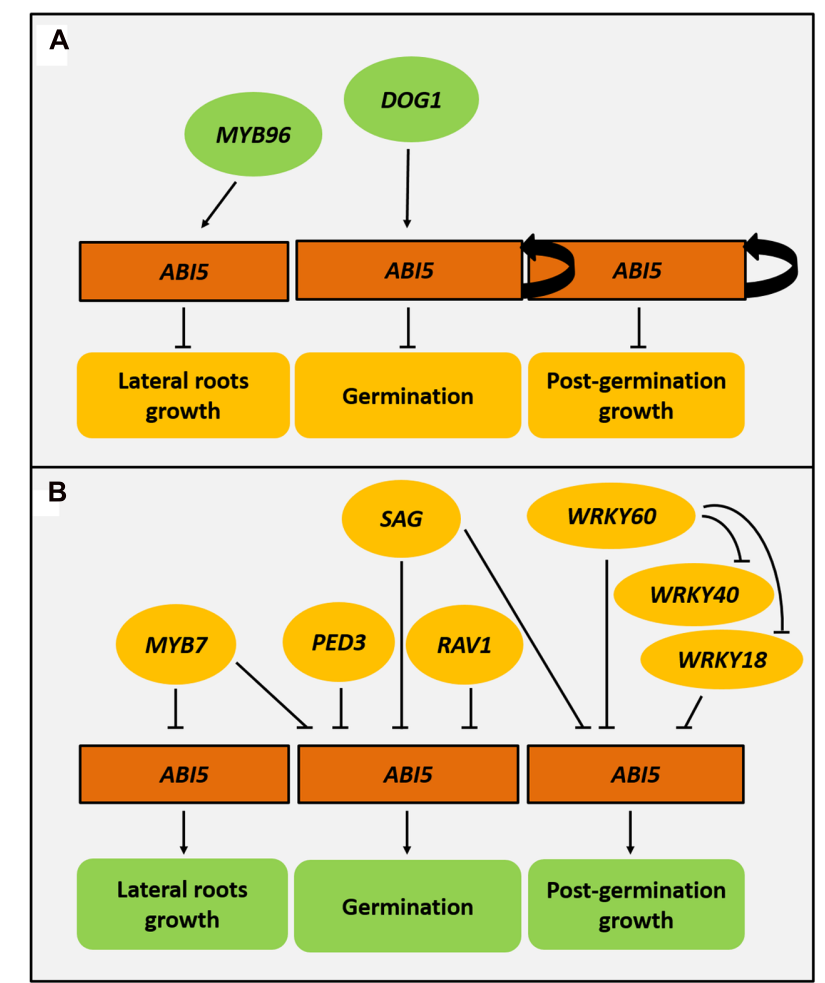

FIGURE 2 | Regulatory genes that control $\boldsymbol{A B I 5}$ expression. $A B I 5$ (ABA INSENSITIVE5) is positively regulated by the $\mathrm{ABI} 5$ protein thus ensuring a positive feedback loop in ABA signaling. DOG1 (DELAY OF GERMINATION 1) and MYB96 also exert a positive effect on ABI5 expression during germination and lateral root formation, respectively. A higher activity of $A B / 5$ leads to the inhibition of germination, post-germination growth and lateral root formation (A). A group of regulators such as PED3 (PEROXISOME DEFECTIVE 3), SAG (SENSITIVITY TO ABA DURING GERMINATION), RAV1 (RELATED TO $A B \mid 3 / V P 1)$, and $M Y B 7$ downregulate $A B / 5$ expression during seed germination. MYB7 also negatively regulates lateral root formation. WRKY18 (WRKY DNA-BINDING PROTEIN18), WRKY40, WRKY60 and SAG repress $A B / 5$ and enable post-germination growth (B). 
ABI5 mediated responses. Some ABA-dependent components, e.g., PYL8 act contrary to general ABA action (Zhao et al., 2014). Stress-activated transcription factors, like MYB7, can inhibit ABI5 expression (Kim et al., 2015). Additionally, ABI5 itself induces expression of AHT1 (ABA-HYPERSENSITIVE BTB/POZ PROTEIN 1), its negative regulator (Kim et al., 2016). DOG1 (DELAY OF GERMINATION 1) also positively promotes $A B I 5$ activity. It encodes an unknown protein that is associated with seed dormancy and the repression of the germination-associated genes. It was also shown that DOG1 is another regulator of ABI5 expression. Possibly, DOG1 acts as a positive regulator of $A B I 5$ and as a result, activates many LEA and HSP (HEAT SHOCK PROTEIN) genes. Additionally, DOG1 may function together with ABI3 in the regulation of seed maturation (Dekkers et al., 2016) (Figure 2A).

MYBs are another large group of transcription factors that are associated with abiotic stress responses (Reyes and Chua, 2007; Dubos et al., 2010). MYB96 is a negative regulator of lateral root formation and participates part in the plant response to drought and salt stress. Since the expression of $A B I 5$ is activated by MYB96, it supports the role of ABI5 in the ABA-dependent inhibition of lateral root growth (Seo et al., 2009) (Figure 2A).

\section{Negative Regulators of ABI5}

Interestingly, the other MYB transcription factor from the R2R3 subgroup, MYB7, also participates in the ABA-mediated regulation of salt and osmotic stress via $A B I 5$. MYB7 represses ABI5 expression during seed germination. Additionally, MYB7 positively influences the content of anthocyanins, which are crucial pigments in the abiotic stress response. In the presence of salt, the myb7 mutant produces shorter lateral roots. Thus, MYB7 is a positive regulator of lateral root growth under salt stress (Kim et al., 2015) (Figure 2B). These studies clearly suggest that the regulation of ABI5 through MYB96 and MYB7 transcription factors may be essential for ABA-mediated regulation in the context of lateral root development under stress.

In the presence of ABA, SnRK2.2, SnRK2.3 and SnRK2.6 interact and phosphorylate RAV1 (RELATED TO ABI3/VP1), that is a common repressor of ABI3, ABI4, and ABI5. RAV1 activity decreases as the $A B I 5$ represses the expression of EM1 and EM6 encoding LEA proteins (Feng et al., 2014) (Figure 2B). Another example is the SAG (SENSITIVITY TO ABA DURING GERMINATION) with a MDN1 (MIDASIN HOMOLOGUE 1) domain. $\mathrm{SAG}$, a negative regulator of $\mathrm{ABA}$ signaling, inhibits the expression of $A B I 5$ and $A B I 3$ during seed germination and seedling development (Chen et al., 2014) (Figure 2B). WRKYs, transcription factors that belong to a large family in plants, also influence the expression of $A B I$ loci. They contain the WRKY motif in the N-terminal end and bind to W-box that is present in the regulated promoters. WRKYs are well known to be both positive and negative regulators of the stress response (Chen et al., 2010; Chen L. et al., 2012; Ding et al., 2015). Initially, WRKY40 was described as a negative regulator of $\mathrm{ABA}$ signaling through its negative impact on ABI5 (Shang et al., 2010). Then, WRKY18 and WRKY60 were detected as ABI5 regulators. WRKY18, WRKY40 and WRKY60 interact with the $\mathrm{W}$-boxes motifs within the promoter regions of $A B I 5$ and in $A B I 4$, and thus repress their expression. The mechanism of this regulation is complex and is restricted to post-germination growth. In the case of $A B I 5$ regulation, WRKY60 inhibits the binding of WRKY18 and WRKY40 to the $A B I 5$ promoter, while it simultaneously acts as an $A B I 5$ repressor. The authors suggest that $A B I 5$ may be the main target of WRKY action in ABA signaling (Liu et al., 2012) (Figure 2B).

AHT1 (ABA-HYPERSENSITIVE BTB/POZ PROTEIN 1), which is a potential substrate receptor of the CRL3 (CULLINRING E3 LIGASE3) complex, down-regulates ABI5. Interestingly, ABI5 induces AHT1 in an ABA-dependent manner. Thus ABI5 is a part of the negative feedback regulation of ABA signaling. It can be assumed that this kind of regulation ensures a balanced response of germinating seeds to salt or osmotic stress (Kim et al., 2016).

The regulation of transcript level can be also performed by small RNAs. Interestingly, regulation of $A B I 5$ expression can be also performed at the post-transcriptional level via miRNA action. In strawberry (Fragaria $\mathrm{x}$ ananassa Duchesne), FaABI5 is target for Fan-miR73 under control conditions. However, abiotic stresses (salinity, UV-B radiation) downregulate activity of Fan-miR73 what in turn promotes FaABI5 and ABA-dependent response. Similar regulation was observed during fruit ripening (Li et al., 2016).

\section{EPIGENETIC REGULATION OF THE $A B I 5$ GENE}

$A B I 5$ also undergoes epigenetic regulation. Together with $A B I 3$, $A B I 5$ is under the control of PKL (PICKLE), a SWI/SNF class chromatin-remodeling factor. PKL negatively regulates the expression of $A B I 5$ and $A B I 3$ because of the increase in the histone methylation ( $\mathrm{H} 3 \mathrm{~K} 9$ and $\mathrm{H} 3 \mathrm{~K} 27)$ of their promoters and chromatin repression in an ABA-dependent manner. PKL releases the germinating embryos from this inhibition and enables seedling growth under unfavorable conditions (Perruc et al., 2007). Another example of ABI5 epigenetic regulation is the ABA-activated action of HLS1 (HOOKLESS 1), a putative histone acetyltransferase. HLS1 directly interacts with the $A B I 5$ sequence, mediates $\mathrm{H} 3$ acetylation and positively regulates ABI5 expression. Furthermore, HLS1 acts cooperatively with MED18 (MEDIATOR 18), a subunit of MEDIATOR complex, to increase ABI5 expression. HLS1 and MED18 interact physically and probably are the part of the same complex. Using transgenic Arabidopsis plants it was proved that HLS1 and MED18 are engaged in ABA signaling and are tightly related to ABI5 action (Liao et al., 2016).

An increased activity of TE (Transposable Elements) was observed under unfavorable environmental conditions (McCue et al., 2012; Le et al., 2014; Makarevitch et al., 2015). Recently, the mechanism of the modulation of $A B I 5$ expression via TE has been described. Heat stress-activated retrotransposon, ONESEN, 
was integrated into $A B I 5$ and disrupted its expression, possibly through the incorrect progress of the transcription (Ito et al., 2016). Moreover, the ABA insensitivity, which was mediated through the insertion of ONESEN in the ABI5 gene, was heritable. On the other hand, an ABA insensitive phenotype can be recovered by the IBM2 (INCREASE IN BONSAI METHYLATION 2) mediated epigenetic regulation of ONESEN. It is possible that ONESEN has an influence on ABA-related genes thus ensuring not only a short-term response to abiotic stress, but also an evolutionary plant adaptation to adverse environmental conditions (Ito et al., 2016).

\section{ABI5 REGULATION AT THE PROTEIN LEVEL}

ABI5 activity is regulated at the protein level via protein interaction and posttranslational modification (reviewed in Daszkowska-Golec, 2016; Table 1).

\section{Turning on ABI5 into Action}

ABA-related phosphorylation that is mediated by SnRK2 kinases is required for ABI5 stability and activation as a transcription factor (Nakashima et al., 2009). Phosphorylation of ABI5 occurs in three conserved domains that are localized in the N-terminal end of the protein (Lopez-Molina et al., 2002). Three amino acids, Ser-42, Ser-145, and Thr-201, are considered to be the targets for the SnRK2-mediated phosphorylation of ABI5 (Wang Y. et al., 2013).

The stability of the ABI5 protein is regulated through its interaction with other proteins. $\mathrm{ABI} 3$ is well known as an interaction partner and enhancer of ABI5 activity at the protein level (Nakamura et al., 2001). It was shown that in the vegetative tissues, ABI5 was able to induce EM1 and EM6 expression only when accompanied by the activation domain from VP16 (VIRION PROTEIN 16) protein. These reports suggest that ABI5 acts in concert with another regulator in seedlings, such as ABI3 (Bensmihen et al., 2004). ABI5 is not only self-regulated during transcription. As a bZIP transcription factor, ABI5 is able to create homo- or heterodimers. The ABA-dependent autoregulation of ABI5 was observed at the protein level through the possibility of creating homodimers (Nakamura et al., 2001; Lynch et al., 2012). ABI5 and AREB/ABF transcription factors are considered to have a redundant function and similar binding properties. ABI5 was shown to interact with ABF3 (ABA RESPONSIVE ELEMENTS-BINDING FACTOR 3) and ABF1 (ABA RESPONSIVE ELEMENTS-BINDING FACTOR 1). Heterodimers composed of ABI5 and other AREB/ABFs regulate the expression of stress-responsive genes. Additionally, there is a negative reciprocal regulation between $A B I 5$ and $A B F 3$ (Kim et al., 2002; Finkelstein et al., 2005). ABI5 also interacts with other regulators of the ABA pathway such as SnRK2.2, SnRK2.3, AHG1 (ABA-HYPERSENSITIVE GERMINATION 1) and AHG3. This indicates that the core ABA-signaling components regulate the early stages of plant development through the phosphorylation and dephosphorylation of ABI5 (Lynch et al., 2012) (Table 1). Additionally, other kinases and phosphatases that regulate the ABI5 phosphorylation status were also identified. $\mathrm{Ca}^{2+}$ signaling-related kinases - CPK11 (CALCIUM-DEPENDENT PROTEIN KINASE 11) (Lynch et al., 2012) and PKS5, a member of CIPK/PKSs (CALCINEURIN B-LIKE PROTEININTERACTING PROTEIN KINASEs/PROTEIN KINASEs SOS2-LIKE) (Zhou et al., 2015), mediate ABI5 phosphorylation (Table 1). ABI5 dephosphorylation events may be dependent on PP2A (PROTEIN PHOSPHATASE 2A) (Hu et al., 2014) and two catalytic subunits of PP6 (PROTEIN PHOSPHATASE 6), FyPP1 and FyPP3 (Dai et al., 2013) (Table 1). However, the interaction between ABI5 and TAP46 protects active and stable ABI5 from the removal of its phosphate groups by PP2A (PROTEIN PHOSPHATASE 2A). It was shown that TAP46 also binds to PP2A, which can prevent the formation of an ABI5-PP2A complex (Hu et al., 2014).

\section{Turning Off ABI5 via Degradation Processes}

ABI5 is dephosphorylated when there is no abiotic stress. ABI5 that has no phosphorylation groups is neither active nor stable and undergoes degradation that is mediated by the $26 \mathrm{~S}$ proteasome pathway (Lopez-Molina et al., 2001). Ubiquitination and $26 \mathrm{~S}$ proteasome-mediated protein degradation are processes that are directed by three enzymes - ubiquitin protein ligase (E3), ubiquitin-conjugating (E2) and ubiquitin activating

TABLE 1 | Posttranslational modifications of ABI5.

\begin{tabular}{|c|c|c|c|}
\hline $\begin{array}{l}\text { Posttranslational } \\
\text { modification }\end{array}$ & Regulators & Result of posttranslational modification & Reference \\
\hline Phosphorylation & $\begin{array}{l}\text { SnRK2s } \\
\text { CPK11 } \\
\text { PKS5 }\end{array}$ & Activation of $\mathrm{ABI} 5$ action & $\begin{array}{l}\text { Nakashima et al., 2009; } \\
\text { Lynch et al., 2012; } \\
\text { Zhou et al., } 2015\end{array}$ \\
\hline Dephosporylation & $\begin{array}{l}\text { AHG1, AHG3 } \\
\text { PP2A } \\
\text { FyPP1, FyPP3 }\end{array}$ & Deactivation of $\mathrm{ABI} 5$ action & $\begin{array}{l}\text { Lynch et al., 2012; } \\
\text { Hu et al., 2014; } \\
\text { Dai et al., } 2013\end{array}$ \\
\hline Ubiquitination & $\begin{array}{l}\text { KEG } \\
\text { DWA1, DWA2 } \\
\text { (CUL4-based patway) }\end{array}$ & ABI5 proteasomal degradation & $\begin{array}{l}\text { Stone et al., 2006; } \\
\text { Lee et al., } 2010\end{array}$ \\
\hline Sumoylation & SIZ1 & Deactivation via $\mathrm{AB} \mid 5$ location in nuclear bodies & Miura et al., 2009 \\
\hline S-nitrosylation & & ABI5 degradation mediated by KEG and CUL4 ligases & Albertos et al., 2015 \\
\hline
\end{tabular}


(E1) enzymes. RING E3 ligase, KEG (KEEP ON GOING), interacts with $\mathrm{ABI} 5$ and controls its accumulation (Stone et al., 2006) (Table 1). ABA counteracts KEG activity and leads to KEG autoubiquitination (Liu and Stone, 2010). The phosphorylation status of ABI5 probably does not influence the interaction between $\mathrm{ABI} 5$ and $\mathrm{KEG}$ in the absence of ABA (Liu and Stone, 2014). The AFP (ABI FIVE BINDING PROTEIN) family also participates in the control of ABI5 accumulation. Although AFP1 and AFP2 mediate the proteasomal degradation of ABI5, their activity is strictly associated with a precise developmental stage (Garcia et al., 2008). Additionally, ABI5 ubiquitination and degradation can be mediated by CUL4-based (CULLIN 4) E3 ligases. Two proteins, DWA1 (DWD HYPERSENSITIVE TO ABA 1) and DWA2, are involved in this regulation through the binding and marking of ABI5 for degradation (Lee et al., 2010) (Table 1).

The abundance ABI5 is not only controlled by ubiquitination. Sumoylation is the process of the attachment of the SUMO (SMALL UBIQUITIN-RELATED MODIFIER) group to a protein substrate and is regulated by an E1-activating enzyme, E2-conjugating enzyme and E3 ligase (Geiss-Friedlander and Melchior, 2007). SIZ1, a SUMO E3 ligase, negatively regulates ABI5 activity by targeting its lysine K391. However, ABI5 sumoylation prevents its degradation through the ABI5 location in alternative nuclear bodies. This ensures a pool of inactive ABI5 that is not susceptible to degradation (Miura et al., 2009) (Table 1). CRWN1 (CROWDED NUCLEI 1) and CRWN3 proteins were also identified as negative regulators of ABI5 accumulation during seed germination. CRWN3 co-localizes with ABI5 in the nuclear bodies, where it probably mediates its degradation (Zhao et al., 2015).
Recently, ABI5 was shown to be $S$-nitrosylated at cysteine 153. This type of modification leads to the degradation of ABI5 mediated by the CUL4 (CULLIN4) and KEG (KEEP ON GOING) E3 ligases and finally ensures seed germination (Albertos et al., 2015) (Table 1). It should also be stressed that NO also acts as a negative regulator of ABA signaling during stomatal closure (Wang et al., 2015).

To summarize, ABI5 activity and stability is regulated by multiple posttranslational modifications through the actions of many regulators and enzymes.

\section{ABI5 AS THE INTEGRATOR OF ABA AND OTHER PHYTOHORMONE SIGNALING DURING ABIOTIC STRESS}

Although ABA is considered to be the main stress plant hormone, other phytohormones such as auxin, cytokinins (CKs), gibberellic acid (GA), brassinosteroids (BRs) and jasmonic acid (JA) also regulate plant adaptation to an adverse environment. Many of the components that are responsible for the biosynthesis and signaling of auxin, CKs, GA, BRs, and JA were identified as taking part in the plant response to drought and salt stress. The precise action of the regulators that belong to different phytohormone pathways ensures a balanced reaction of a plant to abiotic stress. The auxin, CKs, GA, BRs and JA regulation of drought and salt stress includes crosstalk with ABA. Many ABA-related genes are under the control of other phytohormones. This usually requires an interaction with the $\mathrm{ABA}$ signaling components. Among the many ABA-related regulators, ABI5, which integrates various phytohormone pathways and thus enables appropriate plant stress response, appears to be one of the most important (Table 2).

TABLE 2 | ABI5 function in crosstalk with other phytohormones.

\begin{tabular}{|c|c|c|c|c|}
\hline $\begin{array}{l}\text { Phytohormone } \\
\text { pathway }\end{array}$ & Regulator & Function & Type of interaction with the $A B I 5$ gene or $A B I 5$ protein & Reference \\
\hline Auxin & PIN1 & $\begin{array}{l}\text { Auxin } \\
\text { transporter }\end{array}$ & ABI5 negatively regulates PIN1 accumulation in roots & Yuan et al., 2014 \\
\hline \multirow[t]{2}{*}{ Cytokinin } & $\begin{array}{l}\text { ARR4, ARR5, } \\
\text { ARR6 }\end{array}$ & & Down-regulation of $A B / 5$ expression & Wang et al., 2011 \\
\hline & $\begin{array}{l}\text { AHK4, AHP2, } \\
\text { AHP3, AHP5, } \\
\text { ARR12 }\end{array}$ & & Proteasomal degradation of $\mathrm{ABI} 5$ protein & Guan et al., 2014 \\
\hline \multirow[t]{3}{*}{ Gibberellic Acid } & RGL2 & DELLA protein & Reciprocal positive regulation of $A B / 5$ and $R G L 2$ expression & $\begin{array}{l}\text { Piskurewicz et al., 2008; } \\
\text { Yuan et al., } 2011\end{array}$ \\
\hline & & & $\begin{array}{l}\text { ABI5 and RGL2 together regulate the expression of MFT and } \\
\text { GASA6 }\end{array}$ & $\begin{array}{l}\text { Xi et al., 2010; } \\
\text { Zhong et al., } 2015\end{array}$ \\
\hline & RGA & DELLA protein & $\begin{array}{l}\text { ABI5 and RGA together regulate the expression of MFT and } \\
\text { SOM }\end{array}$ & $\begin{array}{l}\text { Xi et al., 2010; } \\
\text { Lim et al., } 2013\end{array}$ \\
\hline \multirow[t]{2}{*}{ Jasmonic Acid } & MED25 & $\begin{array}{l}\text { Subunit of } \\
\text { MEDIATOR } \\
\text { complex }\end{array}$ & $\begin{array}{l}\text { MED25 enhances MYC2 activity and competes with ABI5 to } \\
\text { bind ABA-responsive gene promoters. } \\
\text { Additionally, MED25 promotes ABI5 degradation. }\end{array}$ & Chen R. et al., 2012 \\
\hline & WRKY57 & $\begin{array}{l}\text { Transcription } \\
\text { factor }\end{array}$ & $\begin{array}{l}\text { WKRY57 negatively regulates JA signaling and interacts with } \\
\text { the } A B / 5 \text { promoter }\end{array}$ & $\begin{array}{l}\text { Jiang et al., 2014; } \\
\text { Su et al., } 2016\end{array}$ \\
\hline Brassinosteroids & $\begin{array}{l}\mathrm{BIN} 2 \\
\mathrm{BZR} 1\end{array}$ & $\begin{array}{l}\text { Kinase } \\
\text { Transcription } \\
\text { factor }\end{array}$ & $\begin{array}{l}\text { BIN2 phosphorylates } \mathrm{ABI} 5 \\
\text { BZR1 negatively regulates the expression of } \mathrm{ABI} 5\end{array}$ & $\begin{array}{l}\text { Hu and Yu, 2014; } \\
\text { Yang et al., } 2016\end{array}$ \\
\hline
\end{tabular}




\section{Role of $A B I 5$ and $A B A$ Signaling in Auxin Pathway Regulation}

Auxin positively regulates plant growth and development via the control of cell division, elongation and differentiation. The role of auxin in abiotic stress adaptation is evident, although the precise mechanism of its action still remains unknown. It was shown that a water deficit negatively influences the auxin content (Du et al., 2013; Bao et al., 2014). The biosynthesis of auxin depends on TAA1 (L-TRYPTOPHAN PYRUVATE AMINOTRANSFERASE 1) and the YUC (YUCCA) gene family (Won et al., 2011). Expression of genes from the $Y U C$ family is negatively regulated by drought (Du et al., 2013). However, a higher amount of endogenous auxin ensures a better tolerance to water deprivation (Shi et al., 2014).

The existence of an interaction between auxin and the ABA pathways is evident. Many processes that are significant for the regulation of abiotic stress responses such as stomata closure (Tanaka et al., 2006) and lateral root formation (Shkolnik-Inbar and Bar-Zvi, 2010; Zhao et al., 2014) are under the control of ABA and auxin The link between ABI5 and auxins was established when PIN1 (PIN-FORMED 1) action was studied.

PIN1, a gene encoding the auxin transporter, showed a decreased expression when osmotic stress was applied (Rowe et al., 2016). Salt stress disturbed the expression of the PIN genes and stabilized AXR3/IAA17, which in turn reduced the size of the root meristem because of the lower auxin level (Liu et al., 2015). Yuan et al. (2014) showed that ABI5 participated in the reduction of the root meristem size through a negative impact on the PIN1 content. A glucose-dependent restriction of the root apical meristem was related to a low auxin level and ABI5-mediated regulation. An enhanced expression of ABI5 resulted in a reduced accumulation of the PIN1 protein, which in turn decreased the number and lengths of root apical meristem cells (Yuan et al., 2014) (Table 2). Therefore, ABI5 can be considered to be part of the interaction between auxin and ABA.

\section{Negative Regulation of ABI5 and ABA Signaling by Cytokinins}

Cytokinins belong to another group of plant hormones that regulate the growth and development of plants, mainly through the induction of cell divisions. CK balance is ensured by IPTs (ISOPENTENYLTRANSFERASEs) and CKXs (CK DEHYDROGENASEs), which are the enzymes that are responsible for the biosynthesis and catabolism of CKs, respectively. CKs generally have a negative impact on the adaptation to abiotic stresses. Application of drought or salt stress reduces the amount of CK in plants (reviewed by Ha et al., 2012; Zwack and Rashotte, 2015). ABA and CKs generally act in an opposite manner under stress conditions (Zwack and Rashotte, 2015). ABA negatively regulates the CK biosynthesis genes such as IPT3 (ISOPENTENYLTRANSFERASE3) and IPT8 and ensures a low CK level under stress conditions (Wang et al., 2011). Interestingly, a CK biosynthesis mutant, ipt1/ipt3/ipt5/ipt7, had a decreased endogenous ABA level and showed an increased ABA sensitivity at the same time (Nishiyama et al., 2011). Possibly, there is a strong link between the ABA and $\mathrm{CK}$ pathways, whose disruption causes changes in the phytohormonal balance and other types of plant reactions under stress.

ARRs (ARABIDOPSIS RESPONSE REGULATORs) participate in the interaction between $\mathrm{ABA}$ and cytokinin under stress where the ABI5 function was highlighted. A triple mutant in the genes encoding the B-type of ARRs, arr1/arr10/arr12 showed an ABA-hypersensitive reaction. Additionally, it was described as drought tolerant, because of the smaller stomatal aperture, a higher anthocyanin biosynthesis and better cell membrane integrity (Nguyen et al., 2016). The A-type negative regulators, ARR4, ARR5 and ARR6, were shown to down-regulate $A B I 5$ expression during seed germination. Furthermore, they have the ability to bind ABI5 at the protein level. This indicates that CKs exert a negative effect on ABI5 and ABA signaling integrally. On the other hand, ABA inhibits the expression of ARR4, ARR5 and ARR6. Thus, ABI5 activity is regulated by $\mathrm{ABA}$ and $\mathrm{CK}$ through ARR4, ARR5 and ARR6 at the same time (Wang et al., 2011) (Table 2). CKs also influence ABI5 function during seedling development. However, it includes another part of CK signaling and acts at a different regulatory level compared to seed germination. CKs counteract the arrest of ABA seedling growth via the negative regulation of $\mathrm{ABI} 5$ at the protein level. It was shown that the action of the $\mathrm{CK}$ signaling components, AHK4, AHP2, AHP3, AHP5 and the B-type regulator, ARR12, promote ABI5 $26 \mathrm{~S}$ proteasomal degradation and stimulate the greening of cotyledons. In this way, CKs enable seedling growth under unfavorable conditions (Guan et al., 2014) (Table 2). Therefore, ABI5 is an important component of $\mathrm{ABA}$ and $\mathrm{CK}$ crosstalk during seed germination and seedling development.

\section{ABI5 Interactions With Negative GA Regulators during Seed Germination under Abiotic Stress}

Gibberellic acid (GA) positively regulates the growth and development of plants primarily during seed germination and the conversion between the vegetative and generative stages. Biosynthesis of GA is dependent on GA3ox (GA 3-OXIDASE) and GA20ox (Hisamatsu et al., 2005; reviewed by Colebrook et al., 2014) activity, while GA catabolism is mediated by GA2ox (Rieu et al., 2008). The GA level is modulated by abiotic stress. In maize (Zea mays), the GA content was reduced in its response to drought (Wang et al., 2008). In Arabidopsis, GA2ox6 and GA20x7 expression was up-regulated by osmotic and salt stress, respectively (Magome et al., 2008; Dubois et al., 2013). The GA signal is perceived by the GID1 (GA INSENSITIVE DWARF 1) receptor, which in turn deactivates the DELLA proteins, which are negative regulators of GA signaling (Griffiths et al., 2006). The regulation of GA signaling under abiotic stress through the action of DELLAs has been described in detail (Achard et al., 2008; Claeys et al., 2012).

ABA acts opposite to GA during abiotic stress conditions and DELLAs play a crucial role in this interaction. DELLA 
proteins are activated when the GA level in cells is low (Tyler et al., 2004; Sun, 2011). They generally exert a positive influence on ABA signaling. The RGL2 (RGA-LIKE 2) protein with a DELLA domain positively influences ABA biosynthesis, probably through a XERICO protein, which in turn stimulates ABI5 expression during seed germination under conditions of a low GA content. Thus, ABI5 activity can be observed in the presence of a high ABA:GA ratio (Piskurewicz et al., 2008) (Table 2). Similar to ABI5, RGL2 is also up-regulated by salt in seeds. Furthermore, RGL2 and ABI5 exert a positive effect on each other at the level of gene expression and together regulate seed germination and early seedling growth in the presence of salt (Yuan et al., 2011) (Table 2). Recently, the role of NFYC (NUCLEAR FACTORY C) proteins was shown in RGL2dependent ABI5 expression activation. NF-YC3, NF-YC4 and NF-YC9 are able to form complex with RGL2 and bind to CCAAT elements present in $A B I 5$ promoter. As the result, the transcription of $A B I 5$ is promoted and seed germination is inhibited (Liu et al., 2016). ABI5 and DELLA proteins also regulate a set of the same target genes. MFT (MOTHER OF FT AND TFL 1) encoding a phosphatidylethanolamine-binding protein is expressed in the radical-hypocotyl transition zone and releases seed germination from an inhibitory ABA effect. The activity of MFT is up-regulated during seed germination by ABI5, RGL2 and another DELLA protein, RGA (REPRESSOR OF GA). Additionally, MFT down-regulates the expression of $A B I 5$, thus providing the negative feedback loop in $A B A$ signaling if the $\mathrm{ABA}$ content is too high during seed germination. MFT regulation by the ABI5 and DELLA proteins is part of the mechanism that ensures an appropriate seed germination potential according to the environmental conditions (Xi et al., 2010) (Table 2).

Another common ABI5 and RGA target gene, SOM (SOMNUS), regulates germination under heat stress. SOM expression is activated by $\mathrm{ABA}$ and inactivated by GA with the participation of ABI5 and RGA. They bind each other at specific motifs within the promoter region of SOM and activate its expression in the presence of a high temperature. The action of another DELLA protein, GAI (GA INSENSITIVE), is also possible in the regulation of SOM expression. The activity of SOM, a zinc finger protein, represses seed germination through the simultaneous promotion of ABA biosynthesis and the inhibition of GA biosynthesis. In this way, SOM can create a positive feedback loop with $A B I 5$ and $R G A$ (Lim et al., 2013) (Table 2). ABI5 and the DELLA protein, RGL2, also regulate seed germination via the ABA-dependent inhibition of GASA6 (GIBBERELLIC ACID-STIMULATED ARABIDOPSIS 6) expression. GASA6 acts as a positive regulator of seed germination under abiotic stress. Under a high GA level, GASA6 activates EXPA1 (EXPANSIN A1) encoding cell wall loosening expansin, which in turn stimulates the elongation of the embryonic axis and seed germination. Regulation of GASA6 indicates a direct link between ABI5, RGL2 and the inhibition of seed germination (Zhong et al., 2015) (Table 2). Thus, ABI5 plays the role of GA-signaling modulator, which leads to the repression of seed germination under unfavorable conditions.

\section{Modulation of ABI5 and JA Signaling by Common Protein Regulators}

Jasmonic acid plays a role that is similar to ABA during abiotic stress and ensures plant adaptation to limited water conditions (Riemann et al., 2015). JA positively regulates stress-adaptive processes such as stomatal closure and the activity of antioxidant enzymes (reviewed by Suhita et al., 2003; Qiu et al., 2014). JA signaling is mediated through JAZ (JASMONATE-ZIM-DOMAIN PROTEIN) repressors and MYC (MYELOCYTOMATOSIS) transcription factors. In the presence of JA, MYCs are released from the JAZ-MYC complexes and activate the expression of JA-responsive genes (Chini et al., 2007; Dombrecht et al., 2007). ABA and JA signaling show a strong link. During stomata closure, the increase of ROS and NO content is the result of the $\mathrm{ABA}$ and JA action (Munemasa et al., 2007). It was recently shown that the ABA receptor, PYR6, interacts with MYC2. This suggests a close interaction between the ABA and JA pathways (Aleman et al., 2016). ABI5 also seems to participate in the ABA-JA crosstalk. The activity of ABI5 and MYC2 is modulated at the protein level via the same subunit of the MEDIATOR complex - MED25. The expression of ABA-related genes such as EM1, EM2 and RAB18 and JA-responsive genes including VSP1 (VEGETATIVE STORAGE PROTEIN 1), LOX2 (LIPOXYGENASE 2), JAZ6, JAZ8 is regulated in an opposite manner by MED25. In JA signaling, MED25 acts as a positive regulator through its interaction with MYC2 in the promoter region of the JA-responsive genes. On the other hand, the presence of MED25 in the promoter regions of ABA-responsive genes represses their expression through the prevention of ABI5 binding to the ABRE elements. Additionally, MED25 enhances ABI5 protein degradation (Chen R. et al., 2012) (Table 2). Thus, ABI5 and the component of JA signaling, MYC2, are under control of a common regulator, MED25. JA signaling can also modify the expression of ABI5 through WRKY57 activity. The WRKY57 transcription factor acts as a negative regulator of JA-induced leaf senescence. The activity of JAZ proteins leads to the degradation of WRKY57 (Jiang et al., 2014). Recently, it was shown that WRKY57 interacts with the ABI5 promoter. This suggests that WRKY57 influences the ABI5 expression (Su et al., 2016) (Table 2). Possibly, WRKY57 can link JA and ABA signaling via ABI5 regulation.

\section{ABI5 As a Target of Negative Regulators of BR Signaling}

Brassinosteroids are steroid hormones that regulate a wide range of physiological processes in plant life cycle. Two last decades have witnessed a significant advance in the deciphering the molecular mechanisms underlying BR signaling from perception to regulation of transcription factors influencing expression of target genes. It has been reported that some of the components of BR signaling pathway act as multifunctional proteins involved in other signaling networks, such as the signaling cascades of other hormones, regulating diverse physiological processes (reviewed in Gruszka, 2013). 
ABI5 was shown to be a target of important brassinosteroid signaling components such as BIN2 (BrassinosteroidInsensitive2) and BZR1 (Brassinazole-Resistant1). BIN2 is a kinase functioning as a major negative regulator of $\mathrm{BR}$ signaling through BZR1 and BES1 inactivation. The BZR1 and BES1/BZR2 (BRI1-EMS-Supressor1/Brassinazole-Resistant2) transcription factors are key elements mediating BR-regulated gene expression in A. thaliana. It was reported that these factors bind to promoters of numerous genes involved in signaling and synthesis pathways of GAs, ABA, ethylene, cytokinins and jasmonate, suggesting that BR signaling impacts metabolism of several other plant hormones (Sun et al., 2010; Yu et al., 2011).

It was proved that BIN2 plays important role during seed germination and also in abiotic stress response in ABA-mediated pathway (Yang et al., 2012). BIN2 phosphorylates and stabilizes $\mathrm{ABI} 5$ in order to mediate ABA response during seed germination. Contrary, the exogenously applied BRs repress the BIN2-ABI5 interaction and thus antagonize ABA-mediated inhibition of seed germination ( $\mathrm{Hu}$ and $\mathrm{Yu}, 2014)$. Interestingly, it was also shown that BIN2 can interact and phosphorylate Snf-1-related kinase 2s (SnRK2s), SnRK2.2 and SnRK2.3, positive regulators of ABA signaling that act upstream the ABI5 (Cai et al., 2014).

Yang et al. (2016) showed that bzr1-1D, a dominant mutant with enhanced BR signaling, was less sensitive to ABA-inhibited primary root growth. ABA INSENSITIVE5 (ABI5) was found to be repressed not only by exogenously applied BR but also by BZR1 itself. BZR1 could bind strongly with several G-box ciselements in the promoter of ABI5 suppressing its expression and further resulting in insensitivity to ABA. Taking these results together it was demonstrated that ABI5 is a direct target gene of BZR1, and modulating the expression of ABI5 by BZR1 plays important roles in regulating the crosstalk between the $\mathrm{BR}$ and ABA signaling pathways.

\section{FUNCTION OF ABI5 ORTHOLOGS IN DICOT AND MONOCOT PLANTS DURING ABIOTIC STRESS}

Arabidopsis ABI5 orthologs have been identified in other dicot plants and their sequences are available in bioinformatic databases. However, their precise function under abiotic stresses was described only for a few species. In Brassica oleracea, BolABI5 was found as a close homolog of AtABI5. BolABI5 is expressed mainly in flowers. BolABI5 overexpression in abi5 rescued ABA insensitive phenotype during seed germination. Additionally, application of ABA, drought, salt and osmotic stress activated BolABI5 expression and indicated its role in abiotic stress adaptation. Similar to AtABI5, BolABI5 activates expression of target genes through binding to ABRE elements present in their promoters (Zhou et al., 2013). BolABI5 possesses the ability to interact with BolOST1, a homolog of SnRK2.6/OST1. Probably, BolOST1 is responsible for its phosphorylation and activation as a transcription factor (Wang M. et al., 2013). Two AtABI5 orthologs, $B r A B I 5 a$ and $B r A B I 5 b$, were identified in Brassica rapa. Both are able to reverse abi5 phenotype in the presence of ABA during seed germination. BrABI5a and BrABI5b show a high similarity to ABI5 including conservation of phosphorylation sites. Expression of $\mathrm{BrABI} 5$ genes is activated by ABA treatment; however they act differently in the presence of abiotic stresses. Only $B r A B I 5 b$ is induced by drought and salt. Probably they play a different role in the adaption to unfavorable conditions (Bai et al., 2016).

The role of $A B I 5$ homologs in other dicots was also reported. The expression of SIABI5 in tomato (Solanum lycopersicum) increased in seeds in reponse to ABA (Sun et al., 2015). The function of Medicaco truncatula AtABI5 homolog, MtABI5, was described in more detail, using an insertional mtabi5 mutant. Similarly to atabi5, mtabi5 was ABA-insensitive during seed germination. Furthermore, the level of seed dormancy was decreased in mtabi5. Expression analysis showed reduced expression of LEAs, and SIP1 (SEED IMBIBITION1) encoding raffinose synthase in mtabi5 seeds, while photosynthesis-related genes, e.g., LHCA1 (PHOTOSYSTEM I LIGHT HARVESTING COMPLEX GENE 1) and PsaD-2 (PHOTOSYSTEM I SUBUNIT $D$-2) were up-regulated. MtABI5 acts as the seed development regulator through the control of RFO (RAFFINOSE FAMILY OLIGOSACCHARYDES) and LEA synthesis. Additionally, it serves as a repressor of photosynthesis and accumulation of chlorophyll and carotenoids (Zinsmeister et al., 2016). Recently, action of FaABI5 in strawberry (Fragaria $\mathrm{x}$ ananassa Duchesne) has been also described. It regulates fruit ripening and responses to such as salinity and UV-B radiation (Li et al., 2016). The above results confirm the conserved role of ABI5 orthologs in dicot species. However, further studies are needed in order to reveal their accurate function.

Nowadays, the abiotic stress tolerance of monocot plants is a very important issue. An accurate understanding of the stressrelated mechanisms in monocots can help to improve cereal growth and yield in adverse environments. One of the areas of interest is the ABA-dependent regulation of the stress response in cereals, which includes the action of ABI5.

Although AtABI5 orthologs have been identified in monocot plants, their precise function still remains elusive. HvABI5 is a barley bZIP transcription factor that has high similarity to AtAREB2 and AtABI5 (Casaretto and Ho, 2003). The potential phosphorylation sites of HvABI5 are strongly conserved. The role of barley $H v A B I 5$ in abiotic stress responses is very poorly understood. It is already known that HvABI5 directly, in ABAdependent way, activates the HVA1 and HVA22 expression through binding to the ABRC (ABA RESPONSE PROMOTER COMPLEX) elements within their promoters. However, HvVP1 (VIVIPAROUS1), a homolog of AtABI3, is also required for the activation of HVA1 and HVA22 expression. HVA1 and HVA22 encode, respectively, a group 3 LEA protein and a protein that is involved in vesicular trafficking. Their activity was shown to ensure tolerance to low water availability during seed germination (Casaretto and Ho, 2003). Induction of $\mathrm{HvABI5}$ expression has also been detected in leaves after drought treatment in different barley varieties (de Mezer et al., 2014). In rice, OsABI5 shows a high homology to ABI5 and HvABI5 and had the ability to bind the G-box element (Zou et al., 2008). Like ABI5, OsABI5 interacts with the AtABI3 ortholog OsVP1. Overexpression of OsABI5 in an abi5 Arabidopsis mutant rescued 


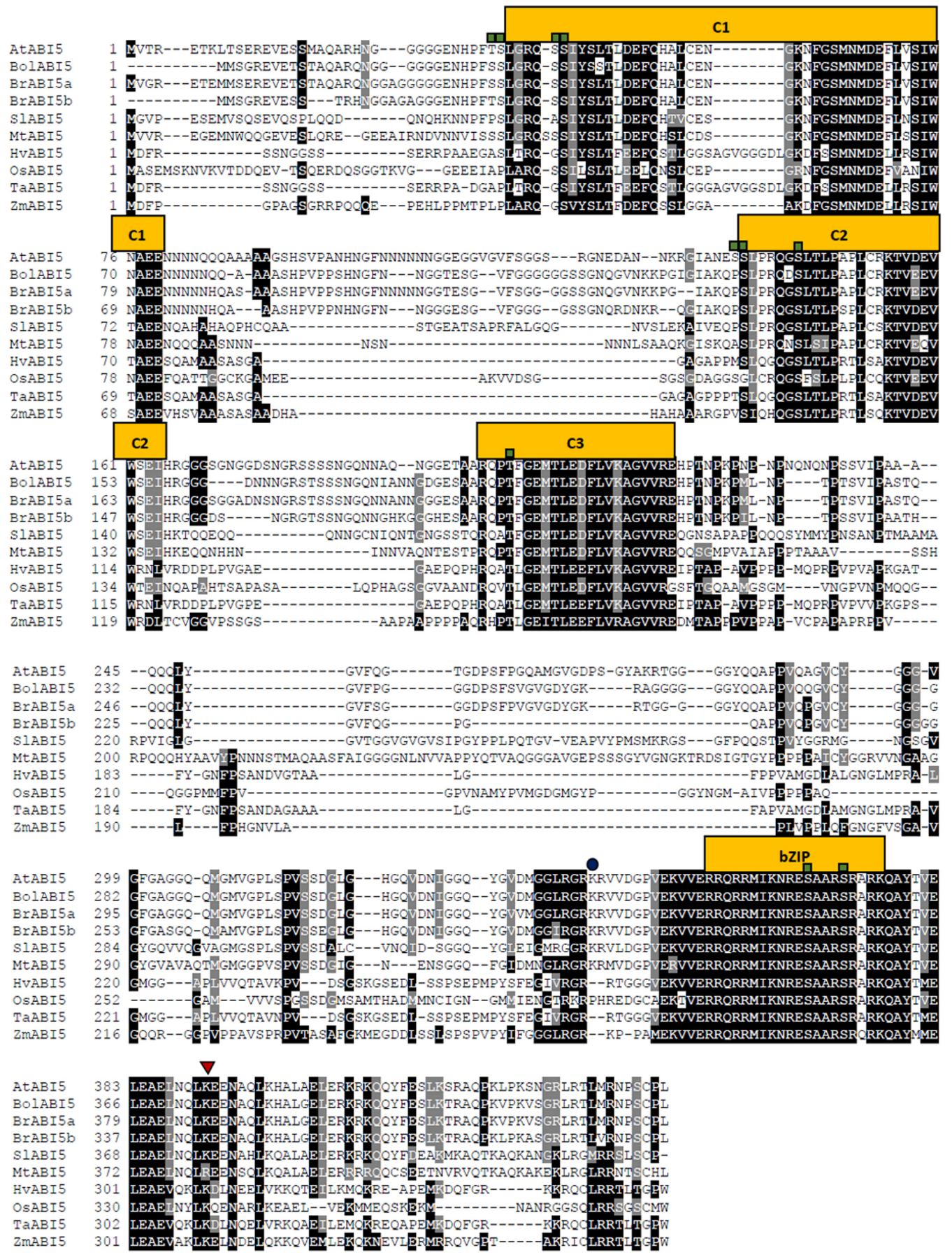

FIGURE 3 | Alignment of ABI5 proteins from 9 species including dicots and monocots orthologs. The square, triangle and circle mark phosphorylation, sumoylation and ubiquitination sites respectively. The alignment was generated using Clustal Omega (https://www.ebi.ac.uk/Tools/msa/clustalo/) and Boxshade (http://www.ch.embnet.org/software/BOX_form.html) softwares. C1, C2, C3 - conserved regions, bZIP - basic leucine zipper domain.

ABA-insensitive phenotype. This could be proof that AtABI5 and OsABI5 share similar functions (Zou et al., 2007). OsABI5 expression is induced by ABA and salt, but drought and cold stress represses its activity. Forty-five-day-old plants of OsABI5overexpression lines showed a faster turgor loss, chlorosis and growth inhibition in the presence of salt. Conversely, OsABI5antisense plants were described as being salt tolerant with a changed expression of SalT, a salt-responsive gene and SKC1, which is a QTL (Quantitative Trait Locus) encoding a sodium transporter. Possibly, OsABI5 acts as an ABA-dependent negative 


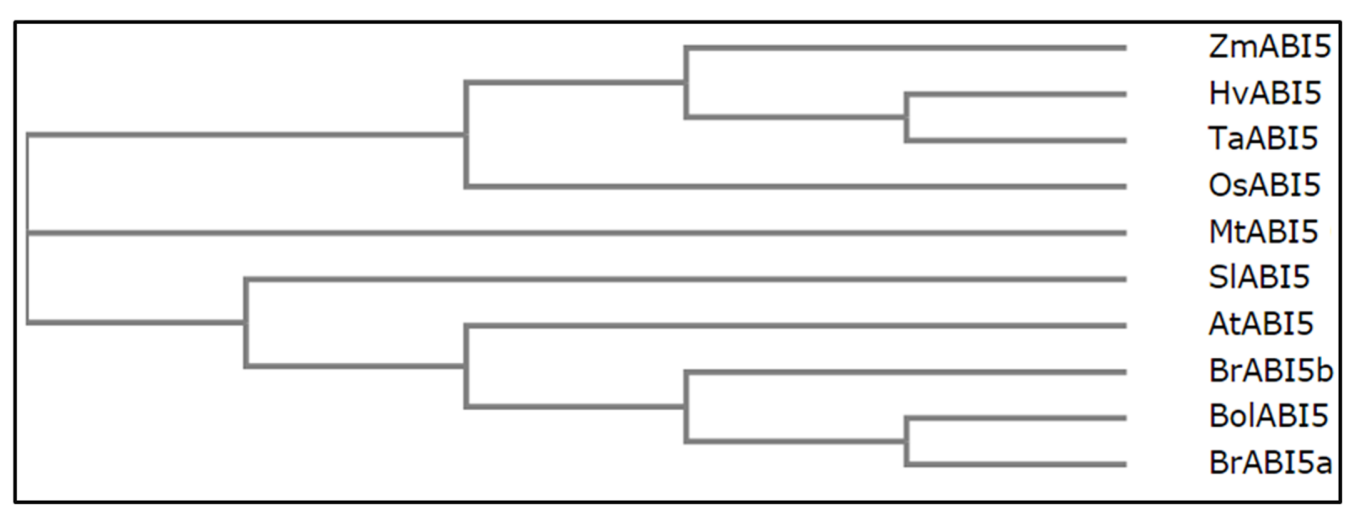

FIGURE 4 | Relationships between AtABI5 and its orthologs. Phylogenetic tree was generated using Clustal Omega software (https://www.ebi.ac.uk/Tools/msa/clustalo/).

regulator of stress tolerance in rice. Furthermore, the fertility of OsABI5-antisense lines was lower than in the wild type due to unsettled pollen formation. It is possible that OsABI5 can also regulate pollen maturation (Zou et al., 2008).

In wheat, $\mathrm{TaABI} 5$ is closely related to HvABI5. Its expression is induced by ABA, drought and low temperature. Two-week-old seedlings of TaABI5-overexpression tobacco (Nicotiana tabacum) lines showed a better survival rate in freezing temperature (Kobayashi et al., 2008). Additionally, 7-day-old seedlings of transgenic lines were more tolerant to salt and osmotic stress and had a higher percentage of green cotyledons compared to the wild type. The opposite effect of the enhanced expression of TaABI5 and OsABI5 on abiotic stress tolerance may be the result of the different developmental stages of the analyzed plants. Furthermore, their function in ABA-activated signaling cannot be equivalent. The root growth of TaABI5-overexpresssion seedlings was ABA-hypersensitive (Kobayashi et al., 2008). Additionally, TaABI5-regulated stress-responsive genes, TaDHN13, TaRAB18 and TaRAB19, were identified (Kobayashi et al., 2008).

$Z m A B I 5$ in maize shows a homology to AtABI5 and HvABI5. The expression of $Z m A B I 5$ is activated by ABA, SA (salicylic acid) salt, cold and heat stress. On the other hand, ZmABI5 was downregulated by drought and wounding in the leaves. However, drought and wounding stress activated $Z m A B I 5$ in roots, while $\mathrm{ABA}$ and salt treatments repressed its activity. Twenty-oneday-old seedlings of tobacco ZmABI5-transgenic lines showed a lower tolerance to drought, salt, heat and cold compared to the wild type. Chlorophyll content, proline accumulation and the activity of antioxidant enzymes, POD (PEROXIDASE) and SOD (SUPEROXIDE DISMUTASE) were decreased in transgenic lines under drought, salt, cold and heat stress (Yan et al., 2012). After stress application, ZmABI5-overexpressed plants also had a higher amount of MDA (MALONDIALDEHYDE), which is an indicator of oxidative damage. Furthermore, salt and heat caused a lower induction of stress-related genes such as CAT1, APX, ERDIOA-D (EARLY RESPONSE TO DEHYDRATION) and PR5 (PATHOGENESIS-RELATED 5) in plants with an overexpression of $\mathrm{ZmABI5}$ compared to the wild type, while under osmotic and cold stress, the expression of these genes was up- or down-regulated. The changed expression of stressresponse genes in transgenic plants indicates the complex role of $\mathrm{ZmABI5}$ in responses to adverse conditions depending on the type of the stress that is applied. It can be assumed that $Z m A B I 5$, like OsABI5, acts as a negative regulator of the abiotic stress response (Yan et al., 2012). The results presented above indicate that monocot AtABI5 orthologs may participate in abiotic stress responses in different ways. Possibly, their action is related to the stage of plant development. Additionally, the mechanism of action of particular orthologs may not be the same in different monocot species. Furthermore, AtABI5 orthologs can also function in different ways depending on the type of stress.

The multiple sequence alignment presents the level of similarity between the described dicot and monocot orthologs (Figure 3). Across the species, the most conserved domain in AtABI5 is a bZIP domain. Conversely, C1 conserved region seems to be weakly preserved, especially in monocots. In other species, AtABI5 phosphorylation sites are mainly maintained in conserved domains. Interestingly, the site for the ubiquitination seems to be characteristic only for the dicots. Probably, another amino acid position is ubiquitinated in monocot plants. The sumoylation site is conserved across AtABI5 homologs. The analysis of ABI5 sequences in different species shows the divergence between dicot and monocot ABI5 forms what can result in its different action in grasses. The relationship between AtABI5 dicot and monocot orthologs is also included on the phylogenetic tree (Figure 4). AtABI5 seems not to show higher similarity to any from described dicot orthologs. The further distance between TaABI5 and OsABI5 may reflect their contrast function under abiotic stress.

\section{CONCLUDING REMARKS}

Plant abiotic stress responses require a complex and accurate regulation. This is achieved through the operation of many regulators that have a modulated activity depending on the water status in the environment. ABI5 seems to be an ABA signaling 
regulator that integrates many different signals and influences the expression of stress-responsive genes. Many processes such as seed germination, seedling growth, photosynthesis and lateral root development were shown to be regulated by ABI5. The mode of the $A B I 5$ gene and $A B I 5$ protein regulation is complex and requires many transcription factors, enzymes and protein regulators. ABI5 expression is the outcome of the action of many transcription factors such as WRKY and MYB as well as epigenetic events. Additionally, multiple protein interactions and posttranslational modifications such as phosphorylation, ubiquitination, sumoylation and $S$-nitrosylation modulate ABI5 activity at the protein level. The action of ABI5 is also related to components of auxin, CK, GA, BR and JA signaling and metabolism pathways. The complicated network of ABI5 connections often results in a positive or negative ABA signaling feedback loop. Finally, the elaborate ABI5 functions ensure a balanced and adequate, respective to the intensity of stress response to adverse conditions. Further studies that are performed using monocot $A B I 5$ homologs and investigations

\section{REFERENCES}

Acevedo-Hernández, G. J., León, P., and Herrera-Estrella, L. R. (2005). Sugar and ABA responsiveness of a minimal RBCS light-responsive unit is mediated by direct binding of ABI4. Plant J. 43, 506-519. doi: 10.1111/j.1365-313X.2005. 02468.x

Achard, P., Renou, J. P., Berthomé, R., Harberd, N. P., and Genschik, P. (2008). Plant DELLAs restrain growth and promote survival of adversity by reducing the levels of reactive oxygen species. Curr. Biol. 18, 656-660. doi: 10.1016/j.cub. 2008.04.034

Albertos, P., Romero-Puertas, M. C., Tatematsu, K., Mateos, I., Sánchez-Vicente, I., Nambara, E., et al. (2015). S-nitrosylation triggers ABI5 degradation to promote seed germination and seedling growth. Nat. Commun. 6, 8669. doi: 10.1038/ ncomms 9669

Aleman, F., Yazaki, J., Lee, M., Takahashi, Y., Kim, A. Y., Li, Z., et al. (2016). An ABA-increased interaction of the PYL6 ABA receptor with MYC2 transcription factor: a putative link of ABA and JA signaling. Sci. Rep 6, 28941. doi: 10.1038/ srep28941

Bai, Y., Zhu, W., Hu, X., Sun, C., Li, Y., Wang, D., et al. (2016). Genome-Wide Analysis of the bZIP Gene Family Identifies Two ABI5-Like bZIP Transcription Factors, BrABI5a and BrABI5b, as Positive Modulators of ABA Signalling in Chinese Cabbage. PLoS ONE 11:e0158966. doi: 10.1371/journal.pone.0158966

Banerjee, A., and Roychoudhury, A. (2015). Abscisic-acid-dependent basic leucine zipper (bZIP) transcription factors in plant abiotic stress. Protoplasma doi: 10.1007/s00709-015-0920-4 [Epub ahead of print].

Bao, Y., Aggarwal, P., Robbins, N. E., Sturrock, C. J., Thompson, M. C., Tan, H. Q., et al. (2014). Plant roots use a patterning mechanism to position lateral root branches toward available water. Proc. Natl. Acad. Sci. U.S.A. 111, 9319-9324. doi: 10.1073/pnas.1400966111

Bensmihen, S., To, A., Lambert, G., Kroj, T., Giraudat, J., and Parcy, F. (2004). Analysis of an activated ABI5 allele using a new selection method for transgenic Arabidopsis seeds. FEBS Lett. 561, 127-131. doi: 10.1016/S0014-5793(04) 00148-6

Bossi, F., Cordoba, E., Dupré, P., Mendoza, M. S., Román, C. S., and León, P. (2009). The Arabidopsis ABA-INSENSITIVE (ABI) 4 factor acts as a central transcription activator of the expression of its own gene, and for the induction of ABI5 and SBE2.2 genes during sugar signaling. Plant J. 59, 359-374. doi: 10.1111/j.1365-313X.2009.03877.x

Brocard, I. M., Lynch, T. J., and Finkelstein, R. R. (2002). Regulation and role of the Arabidopsis ABSCISIC ACID-INSENSITIVE 5 gene in abscisic acid, sugar, and stress response. Plant Physiol. 129, 1533-1543. doi: 10.1104/pp.005793

Cai, Z., Liu, J., Wang, H., Yang, C., Chen, Y., Li, Y., et al. (2014). GSK3-like kinases positively modulate abscisic acid signaling through phosphorylating subgroup of their precise actions in the presence of abiotic stress can be very helpful in obtaining cultivars that have a better stress tolerance.

\section{AUTHOR CONTRIBUTIONS}

AS wrote the manuscript and prepared figures. AD-G and IS contributed to the writing of manuscript and revised it critically for important intellectual content.

\section{FUNDING}

This work was supported by the European Regional Development Fund through the Innovative Economy for Poland 20072013, project WND-POIG.01.03.01-00-101/08 POLAPGEN-BD "Biotechnological tools for breeding cereals with increased resistance to drought," task 22.

III SnRK2s in Arabidopsis. Proc. Natl. Acad. Sci. U.S.A. 111, 9651-9656. doi: 10.1073/pnas.1316717111

Carles, C., Bies-Etheve, N., Aspart, L., Léon-Kloosterziel, K. M., Koornneef, M., Echeverria, M., et al. (2002). Regulation of Arabidopsis thaliana Em genes: role of ABI5. Plant J. 30, 373-383. doi: 10.1046/j.1365-313X.2002. 01295.x

Casaretto, J., and Ho, T. H. D. (2003). The transcription factors HvABI5 and HvVP1 are required for the abscisic acid induction of gene expression in barley aleurone cells. Plant Cell 15, 271-284. doi: 10.1105/tpc.007096

Chen, C., Wu, C., Miao, J., Lei, Y., Zhao, D., Sun, D., et al. (2014). Arabidopsis SAG protein containing the MDN1 domain participates in seed germination and seedling development by negatively regulating $\mathrm{ABI} 3$ and ABI5. J. Exp. Bot. 65, 35-45. doi: 10.1093/jxb/ert343

Chen, H., Lai, Z., Shi, J., Xiao, Y., Chen, Z., and Xu, X. (2010). Roles of Arabidopsis WRKY18, WRKY40 and WRKY60 transcription factors in plant responses to abscisic acid and abiotic stress. BMC Plant Biol. 10:281. doi: 10.1186/1471-222910-281

Chen, L., Song, Y., Li, S., Zhang, L., Zou, C., and Yu, D. (2012). The role of WRKY transcription factors in plant abiotic stresses. Biochim. Biophys. Acta 1819, 120-128. doi: 10.1016/j.bbagrm.2011.09.002

Chen, R., Jiang, H., Li, L., Zhai, Q., Qi, L., Zhou, W., et al. (2012). The Arabidopsis mediator subunit MED25 differentially regulates jasmonate and abscisic acid signaling through interacting with the MYC2 and ABI5 transcription factors. Plant Cell 24, 2898-2916. doi: 10.1105/tpc.112.098277

Chini, A., Fonseca, S., Fernandez, G., Adie, B., Chico, J. M., Lorenzo, O., et al. (2007). The JAZ family of repressors is the missing link in jasmonate signalling. Nature 448, 666-671. doi: 10.1038/nature06006

Claeys, H., Skirycz, A., Maleux, K., and Inzé, D. (2012). DELLA signaling mediates stress-induced cell differentiation in Arabidopsis leaves through modulation of anaphase-promoting complex/cyclosome activity. Plant Physiol. 159, 739-747. doi: 10.1104/pp.112.195032

Colebrook, E. H., Thomas, S. G., Phillips, A. L., and Hedden, P. (2014). The role of gibberellin signalling in plant responses to abiotic stress. J. Exp. Biol. 217, 67-75. doi: 10.1242/jeb.089938

Dai, M., Xue, Q., Mccray, T., Margavage, K., Chen, F., Lee, J. H., et al. (2013). The PP6 phosphatase regulates ABI5 phosphorylation and abscisic acid signaling in Arabidopsis. Plant Cell 25, 517-534. doi: 10.1105/tpc.112.105767

Daszkowska-Golec, A. (2011). Arabidopsis seed germination under abiotic stress as a concert of action of phytohormones. OMICS 15, 763-774. doi: 10.1089/omi. 2011.0082

Daszkowska-Golec, A. (2016). "The role of abscisic acid in drought stress: how aba helps plants to cope with drought stress," in Drought Stress Tolerance in Plants, Vol. 2, eds M. A. Hossain, S. H. Wani, S. Bhattachajee, D. J. Burritt, 
and L. S. P. Tran (Cham: Springer International Publishing), 123-151. doi: 10.1007/978-3-319-32423-4_5

Daszkowska-Golec, A., Wojnar, W., Rosikiewicz, M., Szarejko, I., Maluszynski, M., Szweykowska-Kulinska, Z., et al. (2013). Arabidopsis suppressor mutant of abh1 shows a new face of the already known players: ABH1 (CBP80) and ABI4 - in response to $\mathrm{ABA}$ and abiotic stresses during seed germination. Plant Mol. Biol. 81, 189-209. doi: 10.1007/s11103-012-9991-1

de Mezer, M., Turska-Taraska, A., Kaczmarek, Z., Glowacka, K., Swarcewicz, B., and Rorat, T. (2014). Differential physiological and molecular response of barley genotypes to water deficit. Plant Physiol. Biochem. 80, 234-248. doi: 10.1016/j.plaphy.2014.03.025

De Smet, I., Signora, L., Beeckman, T., Inzé, D., Foyer, C. H., and Zhang, H. (2003). An abscisic acid sensitive checkpoint in lateral root development of Arabidopsis. Plant J. 33, 543-555. doi: 10.1046/j.1365-313X.2003.01652.x

Debeaujon, I., Léon-Kloosterziel, K. M., and Koornneef, M. (2000). Influence of the testa on seed dormancy, germination, and longevity in Arabidopsis. Plant Physiol. 122, 403-414. doi: 10.1104/pp.122.2.403

Dekkers, B. J., He, H., Hanson, J., Willems, L. A., Jamar, D. C., Cueff, G., et al. (2016). The Arabidopsis DELAY OF GERMINATION 1 gene affects ABSCISIC ACID INSENSITIVE 5 (ABI5) expression and genetically interacts with ABI3 during Arabidopsis seed development. Plant J. 85, 451-465. doi: 10.1111/tpj. 13118

Ding, Z. J., Yan, J. Y., Li, C. X., Li, G. X., Wu, Y. R., and Zheng, S. J. (2015). Transcription factor WRKY46 modulates the development of Arabidopsis lateral roots in osmotic/salt stress conditions via regulation of ABA signaling and auxin homeostasis. Plant J. 84, 56-69. doi: 10.1111/tpj.12958

Dombrecht, B., Xue, G. P., Sprague, S. J., Kirkegaard, J. A., Ross, J. J., Reid, J. B., et al. (2007). MYC2 differentially modulates diverse jasmonate-dependent functions in Arabidopsis. Plant Cell 19, 2225-2245. doi: 10.1105/tpc.106.048017

Du, H., Liu, H., and Xiong, L. (2013). Endogenous auxin and jasmonic acid levels are differentially modulated by abiotic stresses in rice. Front. Plant Sci. 4:397. doi: $10.3389 /$ fpls.2013.00397

Dubois, M., Skirycz, A., Claeys, H., Maleux, K., Dhondt, S., De Bodt, S., et al. (2013). ETHYLENE RESPONSE FACTOR6 acts as a central regulator of leaf growth under water-limiting conditions in Arabidopsis. Plant Physiol. 162, 319-332. doi: 10.1104/pp.113.216341

Dubos, C., Stracke, R., Grotewold, E., Weisshaar, B., Martin, C., and Lepiniec, L. (2010). MYB transcription factors in Arabidopsis. Trends Plant Sci. 15, 573-581. doi: $10.1016 / j . t p l a n t s .2010 .06 .005$

Fait, A., Angelovici, R., Less, H., Ohad, I., Urbanczyk-Wochniak, E., Fernie, A. R., et al. (2006). Arabidopsis seed development and germination is associated with temporally distinct metabolic switches. Plant Physiol. 142, 839-854. doi: 10. 1104/pp.106.086694

Feng, C. Z., Chen, Y., Wang, C., Kong, Y. H., Wu, W. H., and Chen, Y. F. (2014). Arabidopsis RAV1 transcription factor, phosphorylated by SnRK2 kinases, regulates the expression of $\mathrm{ABI} 3, \mathrm{ABI} 4$, and $\mathrm{ABI} 5$ during seed germination and early seedling development. Plant J. 80, 654-668. doi: 10.1111/tpj.12670

Finch-Savage, W. E., and Leubner-Metzger, G. (2006). Seed dormancy and the control of germination. New Phytol. 171, 501-523. doi: 10.1111/j.1469-8137. 2006.01787.x

Finkelstein, R., Gampala, S. S., Lynch, T. J., Thomas, T. L., and Rock, C. D. (2005). Redundant and distinct functions of the ABA response loci ABA-INSENSITIVE (ABI) 5 and ABRE-BINDING FACTOR (ABF) 3. Plant Mol. Biol. 59, 253-267. doi: $10.1007 / \mathrm{s} 11103-005-8767-2$

Finkelstein, R. R. (1994). Mutations at two new Arabidopsis ABA response loci are similar to the abi3 mutations. Plant J. 5, 765-771. doi: 10.1046/j.1365-313X. 1994.5060765.x

Finkelstein, R. R., and Lynch, T. J. (2000). The Arabidopsis abscisic acid response gene ABI5 encodes a basic leucine zipper transcription factor. Plant Cell 12, 599-609. doi: 10.1105/tpc.12.4.599

Finkelstein, R. R., and Somerville, C. R. (1990). Three classes of abscisic acid (ABA)-insensitive mutations of Arabidopsis define genes that control overlapping subsets of ABA responses. Plant Physiol. 94, 1172-1179. doi: 10. 1104/pp.94.3.1172

Garcia, M. E., Lynch, T., Peeters, J., Snowden, C., and Finkelstein, R. (2008). A small plant-specific protein family of ABI five binding proteins (AFPs) regulates stress response in germinating Arabidopsis seeds and seedlings. Plant Mol. Biol. 67, 643-658. doi: 10.1007/s11103-008-9344-2
Geiss-Friedlander, R., and Melchior, F. (2007). Concepts in sumoylation: a decade on. Nat. Rev. Mol. Cell Biol. 8, 947-956. doi: 10.1038/nrm2293

Golldack, D., Lüking, I., and Yang, O. (2011). Plant tolerance to drought and salinity: stress regulating transcription factors and their functional significance in the cellular transcriptional network. Plant Cell Rep. 30, 1383-1391. doi: 10.1007/s00299-011-1068-0

Griffiths, J., Murase, K., Rieu, I., Zentella, R., Zhang, Z. L., Powers, S. J., et al. (2006). Genetic characterization and functional analysis of the GID1 gibberellin receptors in Arabidopsis. Plant Cell 18, 3399-3414. doi: 10.1105/tpc.106.047415

Gruszka, D. (2013). The brassinosteroid signaling pathway-new key players and interconnections with other signaling networks crucial for plant development and stress tolerance. Int. J. Mol. Sci. 14, 8740-8774. doi: 10.3390/ijms 14058740

Guan, C., Wang, X., Feng, J., Hong, S., Liang, Y., Ren, B., et al. (2014). Cytokinin antagonizes abscisic acid-mediated inhibition of cotyledon greening by promoting the degradation of abscisic acid insensitive 5 protein in Arabidopsis. Plant Physiol. 164, 1515-1526. doi: 10.1104/pp.113.234740

Ha, S., Vankova, R., Yamaguchi-Shinozaki, K., Shinozaki, K., and Tran, L. S. P. (2012). Cytokinins: metabolism and function in plant adaptation to environmental stresses. Trends Plant Sci. 17, 172-179. doi: 10.1016/j.tplants. 2011.12.005

Hisamatsu, T., King, R. W., Helliwell, C. A., and Koshioka, M. (2005). The involvement of GIBBERELLIN 20-OXIDASE genes in phytochrome-regulated petiole elongation of Arabidopsis. Plant Physiol. 138, 1106-1116. doi: 10.1104/ pp.104.059055

Hu, R., Zhu, Y., Shen, G., and Zhang, H. (2014). TAP46 plays a positive role in the ABSCISIC ACID INSENSITIVE5-regulated gene expression in Arabidopsis. Plant Physiol. 164, 721-734. doi: 10.1104/pp.113.233684

$\mathrm{Hu}, \mathrm{Y}$., and $\mathrm{Yu}, \mathrm{D}$. (2014). BRASSINOSTEROID INSENSITIVE2 interacts with ABSCISIC ACID INSENSITIVE5 to mediate the antagonism of brassinosteroids to abscisic acid during seed germination in Arabidopsis. Plant Cell 26, 4394-4408. doi: 10.1105/tpc.114.130849

Ito, H., Kim, J. M., Matsunaga, W., Saze, H., Matsui, A., Endo, T. A., et al. (2016). A stress-activated transposon in Arabidopsis induces transgenerational abscisic acid insensitivity. Sci. Rep. 6, 23181. doi: 10.1038/srep23181

Jacobsen, J. V., Pearce, D. W., Poole, A. T., Pharis, R. P., and Mander, L. N. (2002). Abscisic acid, phaseic acid and gibberellin contents associated with dormancy and germination in barley. Physiol. Plant. 115, 428-441. doi: 10.1034/j.13993054.2002.1150313.x

Jiang, Y., Liang, G., Yang, S., and Yu, D. (2014). Arabidopsis WRKY57 functions as a node of convergence for jasmonic acid-and auxin-mediated signaling in jasmonic acid-induced leaf senescence. Plant Cell 26, 230-245. doi: 10.1105/ tpc.113.117838

Jones, A. M. (2016). A new look at stress: abscisic acid patterns and dynamics at high-resolution. New Phytol. 210, 38-44. doi: 10.1111/nph.13552

Kanai, M., Nishimura, M., and Hayashi, M. (2010). A peroxisomal ABC transporter promotes seed germination by inducing pectin degradation under the control of ABI5. Plant J. 62, 936-947. doi: 10.1111/j.1365-313X.2010. 04205.x

Kim, H., Kim, S. H., Seo, D. H., Chung, S., Kim, S. W., Lee, J. S., et al. (2016). ABAHYPERSENSITIVE BTB/POZ PROTEIN 1 functions as a negative regulator in ABA-mediated inhibition of germination in Arabidopsis. Plant Mol. Biol. 90, 303-315. doi: 10.1007/s11103-015-0418-7

Kim, J. H., Hyun, W. Y., Nguyen, H. N., Jeong, C. Y., Xiong, L., Hong, S. W., et al. (2015). AtMyb7, a subgroup 4 R2R3 Myb, negatively regulates ABAinduced inhibition of seed germination by blocking the expression of the bZIP transcription factor ABI5. Plant Cell Environ. 38, 559-571. doi: 10.1111/pce. 12415

Kim, S. Y. (2006). The role of ABF family bZIP class transcription factors in stress response. Physiol. Plant. 126, 519-527.

Kim, S. Y., Ma, J., Perret, P., Li, Z., and Thomas, T. L. (2002). Arabidopsis ABI5 subfamily members have distinct DNA-binding and transcriptional activities. Plant Physiol. 130, 688-697. doi: 10.1104/pp.003566

Kobayashi, F., Maeta, E., Terashima, A., and Takumi, S. (2008). Positive role of a wheat HvABI5 ortholog in abiotic stress response of seedlings. Physiol. Plant. 134, 74-86. doi: 10.1111/j.1399-3054.2008.01107.x

Kong, Y., Chen, S., Yang, Y., and An, C. (2013). ABA-insensitive (ABI) 4 and ABI5 synergistically regulate DGAT1 expression in Arabidopsis seedlings under stress. FEBS Lett. 587, 3076-3082. doi: 10.1016/j.febslet.2013.07.045 
Kushiro, T., Okamoto, M., Nakabayashi, K., Yamagishi, K., Kitamura, S., Asami, T., et al. (2004). The Arabidopsis cytochrome P450 CYP707A encodes ABA 8' hydroxylases: key enzymes in ABA catabolism. The EMBO J. 23, 1647-1656. doi: 10.1038/sj.emboj.7600121

Le, T. N., Schumann, U., Smith, N. A., Tiwari, S., Au, P., Zhu, Q. H., et al. (2014). DNA demethylases target promoter transposable elements to positively regulate stress responsive genes in Arabidopsis. Genome Biol. 15, 458. doi: 10.1186/ s13059-014-0458-3

Lee, J. H., Yoon, H. J., Terzaghi, W., Martinez, C., Dai, M., Li, J., et al. (2010). DWA1 and DWA2, two Arabidopsis DWD protein components of CUL4-based E3 ligases, act together as negative regulators in ABA signal transduction. Plant Cell 22, 1716-1732. doi: 10.1105/tpc.109.073783

Li, D., Mou, W., Luo, Z., Li, L., Limwachiranon, J., Mao, L., et al. (2016). Developmental and stress regulation on expression of a novel miRNA, FanmiR73, and its target ABI5 in strawberry. Sci. Rep. 6:28385. doi: 10.1038/ srep 28385

Liao, C. J., Lai, Z., Lee, S., Yun, D. J., and Mengiste, T. (2016). Arabidopsis HOOKLESS1 regulates responses to pathogens and abscisic acid through interaction with MED18 and acetylation of WRKY33 and ABI5 chromatin. Plant Cell 28, 1662-1681. doi: 10.1105/tpc.16.00105

Lim, S., Park, J., Lee, N., Jeong, J., Toh, S., Watanabe, A., et al. (2013). ABA-INSENSITIVE3, ABA-INSENSITIVE5, and DELLAs interact to activate the expression of SOMNUS and other high-temperature-inducible genes in imbibed seeds in Arabidopsis. Plant Cell 25, 4863-4878. doi: 10.1105/tpc.113. 118604

Liu, H., and Stone, S. L. (2010). Abscisic acid increases Arabidopsis ABI5 transcription factor levels by promoting KEG E3 ligase self-ubiquitination and proteasomal degradation. Plant Cell 22, 2630-2641. doi: 10.1105/tpc.110. 076075

Liu, H., and Stone, S. L. (2014). Regulation of ABI5 turnover by reversible posttranslational modifications. Plant Signal. Behav. 9:e27577. doi: 10.4161/psb. 27577

Liu, W., Li, R. J., Han, T. T., Cai, W., Fu, Z. W., and Lu, Y. T. (2015). Salt stress reduces root meristem size by nitric oxide-mediated modulation of auxin accumulation and signaling in Arabidopsis. Plant Physiol. 168, 343-356. doi: $10.1104 /$ pp. 15.00030

Liu, X., Hu, P., Huang, M., Tang, Y., Li, Y., Li, L., et al. (2016). The NF-YCRGL2 module integrates GA and ABA signalling to regulate seed germination in Arabidopsis. Nat. Commun 7:12768. doi: 10.1038/ncomms 12768

Liu, Y., Fang, J., Xu, F., Chu, J., Yan, C., Schläppi, M. R., et al. (2014). Expression patterns of $\mathrm{ABA}$ and GA metabolism genes and hormone levels during rice seed development and imbibition: a comparison of dormant and nondormant rice cultivars. J. Genet. Genomics 41, 327-338. doi: 10.1016/j.jgg.2014. 04.004

Liu, Z. Q., Yan, L., Wu, Z., Mei, C., Lu, K., Yu, Y. T., et al. (2012). Cooperation of three WRKY-domain transcription factors WRKY18, WRKY40, and WRKY60 in repressing two ABA-responsive genes ABI4 and ABI5 in Arabidopsis. J. Exp. Bot. 63, 6371-6392. doi: 10.1093/jxb/ers293

Lopez-Molina, L., Mongrand, S., and Chua, N. H. (2001). A postgermination developmental arrest checkpoint is mediated by abscisic acid and requires the ABI5 transcription factor in Arabidopsis. Proc. Natl. Acad. Sci. U.S.A. 98, 4782-4787. doi: 10.1073/pnas.081594298

Lopez-Molina, L., Mongrand, S., McLachlin, D. T., Chait, B. T., and Chua, N. H. (2002). ABI5 acts downstream of ABI3 to execute an ABA-dependent growth arrest during germination. Plant J. 32, 317-328. doi: 10.1046/j.1365-313X.2002. 01430.x

Lynch, T., Erickson, B. J., and Finkelstein, R. R. (2012). Direct interactions of ABAinsensitive (ABI)-clade protein phosphatase (PP) 2Cs with calcium-dependent protein kinases and $A B A$ response element-binding bZIPs may contribute to turning off ABA response. Plant Mol. Biol. 80, 647-658. doi: 10.1007/s11103012-9973-3

Magome, H., Yamaguchi, S., Hanada, A., Kamiya, Y., and Oda, K. (2008). The DDF1 transcriptional activator upregulates expression of a gibberellindeactivating gene, GA2ox7, under high-salinity stress in Arabidopsis. Plant J. 56, 613-626. doi: 10.1111/j.1365-313X.2008.03627.x

Maia, J., Dekkers, B. J., Dolle, M. J., Ligterink, W., and Hilhorst, H. W. (2014). Abscisic acid (ABA) sensitivity regulates desiccation tolerance in germinated Arabidopsis seeds. New Phytol. 203, 81-93. doi: 10.1111/nph.12785
Makarevitch, I., Waters, A. J., West, P. T., Stitzer, M., Hirsch, C. N., Ross-Ibarra, J., et al. (2015). Transposable elements contribute to activation of maize genes in response to abiotic stress. PLoS Genet. 11:e1004915. doi: 10.1371/journal.pgen. 1004915

Manz, B., Müller, K., Kucera, B., Volke, F., and Leubner-Metzger, G. (2005). Water uptake and distribution in germinating tobacco seeds investigated in vivo by nuclear magnetic resonance imaging. Plant Physiol. 138, 1538-1551. doi: 10. 1104/pp.105.061663

McCue, A. D., Nuthikattu, S., Reeder, S. H., and Slotkin, R. K. (2012). Gene expression and stress response mediated by the epigenetic regulation of a transposable element small RNA. PLoS Genet. 8:e1002474. doi: 10.1371/journal. pgen. 1002474

Mehrotra, R., Bhalothia, P., Bansal, P., Basantani, M. K., Bharti, V., and Mehrotra, S. (2014). Abscisic acid and abiotic stress tolerance-Different tiers of regulation. J. Plant Physiol. 171, 486-496. doi: 10.1016/j.jplph.2013.12.007

Miransari, M., and Smith, D. L. (2014). Plant hormones and seed germination. Environ. Exp. Bot. 99, 110-121. doi: 10.1016/j.envexpbot.2013.11.005

Mitchum, M. G., Yamaguchi, S., Hanada, A., Kuwahara, A., Yoshioka, Y., Kato, T., et al. (2006). Distinct and overlapping roles of two gibberellin 3-oxidases in Arabidopsis development. Plant J. 45, 804-818. doi: 10.1111/j.1365-313X.2005. 02642.x

Miura, K., Lee, J., Jin, J. B., Yoo, C. Y., Miura, T., and Hasegawa, P. M. (2009). Sumoylation of ABI5 by the Arabidopsis SUMO E3 ligase SIZ1 negatively regulates abscisic acid signaling. Proc. Natl. Acad. Sci. U.S.A. 106, 5418-5423. doi: $10.1073 /$ pnas. 0811088106

Munemasa, S., Hauser, F., Park, J., Waadt, R., Brandt, B., and Schroeder, J. I. (2015). Mechanisms of abscisic acid-mediated control of stomatal aperture. Curr. Opin. Plant Biol. 28, 154-162. doi: 10.1016/j.pbi.2015.10.010

Munemasa, S., Oda, K., Watanabe-Sugimoto, M., Nakamura, Y., Shimoishi, Y., and Murata, Y. (2007). The coronatine-insensitive 1 mutation reveals the hormonal signaling interaction between abscisic acid and methyl jasmonate in Arabidopsis guard cells. Specific impairment of ion channel activation and second messenger production. Plant Physiol. 143, 1398-1407. doi: 10.1104/pp. 106.091298

Nakamura, S., Lynch, T. J., and Finkelstein, R. R. (2001). Physical interactions between ABA response loci of Arabidopsis. Plant J. 26, 627-635. doi: 10.1046/j. 1365-313x.2001.01069.x

Nakashima, K., Fujita, Y., Kanamori, N., Katagiri, T., Umezawa, T., Kidokoro, S. et al. (2009). Three Arabidopsis SnRK2 protein kinases, SRK2D/SnRK2. 2, SRK2E/SnRK2. 6/OST1 and SRK2I/SnRK2. 3, involved in ABA signaling are essential for the control of seed development and dormancy. Plant Cell Physiol. 50, 1345-1363. doi: 10.1093/pcp/pcp083

Nakashima, K., and Yamaguchi-Shinozaki, K. (2013). ABA signaling in stressresponse and seed development. Plant Cell Rep. 32, 959-970. doi: 10.1007/ s00299-013-1418-1

Nambara, E., Suzuki, M., Abrams, S., McCarty, D. R., Kamiya, Y., and McCourt, P. (2002). A screen for genes that function in abscisic acid signaling in Arabidopsis thaliana. Genetics 161, 1247-1255.

Nguyen, K. H., Van Ha, C., Nishiyama, R., Watanabe, Y., Leyva-González, M. A., Fujita, Y., et al. (2016). Arabidopsis type B cytokinin response regulators ARR1, ARR10, and ARR12 negatively regulate plant responses to drought. Proc. Natl. Acad. Sci. U.S.A 113, 3090-3095. doi: 10.1073/pnas.1600399113

Nishiyama, R., Watanabe, Y., Fujita, Y., Le, D. T., Kojima, M., Werner, T., et al. (2011). Analysis of cytokinin mutants and regulation of cytokinin metabolic genes reveals important regulatory roles of cytokinins in drought, salt and abscisic acid responses, and abscisic acid biosynthesis. Plant Cell 23, 2169-2183. doi: 10.1105/tpc.111.087395

Nonogaki, H., Bassel, G. W., and Bewley, J. D. (2010). Germination-still a mystery. Plant Sci. 179, 574-581. doi: 10.4161/psb.25504

Ogawa, M., Hanada, A., Yamauchi, Y., Kuwahara, A., Kamiya, Y., and Yamaguchi, S. (2003). Gibberellin biosynthesis and response during Arabidopsis seed germination. Plant Cell 15, 1591-1604. doi: 10.1105/tpc.011650

Okamoto, M., Kuwahara, A., Seo, M., Kushiro, T., Asami, T., Hirai, N., et al. (2006). CYP707A1 and CYP707A2, which encode abscisic acid 8' -hydroxylases, are indispensable for proper control of seed dormancy and germination in Arabidopsis. Plant Physiol. 141, 97-107. doi: 10.1104/pp.106.079475

Perruc, E., Kinoshita, N., and Lopez-Molina, L. (2007). The role of chromatinremodeling factor PKL in balancing osmotic stress responses during 
Arabidopsis seed germination. Plant J. 52, 927-936. doi: 10.1111/j.1365-313X. 2007.03288.x

Piskurewicz, U., Jikumaru, Y., Kinoshita, N., Nambara, E., Kamiya, Y., and LopezMolina, L. (2008). The gibberellic acid signaling repressor RGL2 inhibits Arabidopsis seed germination by stimulating abscisic acid synthesis and ABI5 activity. Plant Cell 20, 2729-2745. doi: 10.1105/tpc.108.061515

Qiu, Z., Guo, J., Zhu, A., Zhang, L., and Zhang, M. (2014). Exogenous jasmonic acid can enhance tolerance of wheat seedlings to salt stress. Ecotoxicol. Environ. Saf. 104, 202-208. doi: 10.1016/j.ecoenv.2014.03.014

Rajjou, L., Duval, M., Gallardo, K., Catusse, J., Bally, J., Job, C., et al. (2012). Seed germination and vigor. Annu. Rev. Plant Biol. 63, 507-533. doi: 10.1146/ annurev-arplant-042811-105550

Reeves, W. M., Lynch, T. J., Mobin, R., and Finkelstein, R. R. (2011). Direct targets of the transcription factors ABA-Insensitive (ABI) 4 and ABI5 reveal synergistic action by ABI4 and several bZIP ABA response factors. Plant Mol. Biol. 75, 347-363. doi: 10.1007/s11103-011-9733-9

Reyes, J. L., and Chua, N. H. (2007). ABA induction of miR159 controls transcript levels of two MYB factors during Arabidopsis seed germination. Plant J. 49, 592-606. doi: 10.1111/j.1365-313X.2006.02980.x

Riemann, M., Dhakarey, R., Hazman, M., Miro, B., Kohli, A., and Nick, P. (2015). Exploring jasmonates in the hormonal network of drought and salinity responses. Front. Plant Sci. 6:1077. doi: 10.3389/fpls.2015.01077

Rieu, I., Eriksson, S., Powers, S. J., Gong, F., Griffiths, J., Woolley, L., et al. (2008). Genetic analysis reveals that C19-GA 2-oxidation is a major gibberellin inactivation pathway in Arabidopsis. Plant Cell 20, 2420-2436. doi: 10.1105/tpc. 108.058818

Rowe, J. H., Topping, J. F., Liu, J., and Lindsey, K. (2016). Abscisic acid regulates root growth under osmotic stress conditions via an interacting hormonal network with cytokinin, ethylene and auxin. New Phytol. 211, 225-239. doi: $10.1111 /$ nph.13882

Roychoudhury, A., Paul, S., and Basu, S. (2013). Cross-talk between abscisic aciddependent and abscisic acid-independent pathways during abiotic stress. Plant Cell Rep. 32, 985-1006. doi: 10.1007/s00299-013-1414-5

Sah, S. K., Reddy, K. R., and Li, J. (2016). Abscisic acid and abiotic stress tolerance in crop plants. Front. Plant Sci. 7:571. doi: 10.3389/fpls.2016.00571

Sakuraba, Y., Jeong, J., Kang, M. Y., Kim, J., Paek, N. C., and Choi, G. (2014). Phytochrome-interacting transcription factors PIF4 and PIF5 induce leaf senescence in Arabidopsis. Nat. Commun. 5:4636. doi: 10.1038/ncomms5636

Seo, P. J., Xiang, F., Qiao, M., Park, J. Y., Lee, Y. N., Kim, S. G., et al. (2009). The MYB96 transcription factor mediates abscisic acid signaling during drought stress response in Arabidopsis. Plant Physiol 151, 275-289. doi: 10.1104/pp.109. 144220

Shang, Y., Yan, L., Liu, Z. Q., Cao, Z., Mei, C., Xin, Q., et al. (2010). The Mgchelatase $\mathrm{H}$ subunit of Arabidopsis antagonizes a group of WRKY transcription repressors to relieve ABA-responsive genes of inhibition. Plant Cell 22, 19091935. doi: $10.1105 /$ tpc. 110.073874

Sharp, R. E., Poroyko, V., Hejlek, L. G., Spollen, W. G., Springer, G. K., Bohnert, H. J., et al. (2004). Root growth maintenance during water deficits: physiology to functional genomics. J. Exp. Bot. 55, 2343-2351. doi: 10.1093/jxb/ erh276

Shi, H., Chen, L., Ye, T., Liu, X., Ding, K., and Chan, Z. (2014). Modulation of auxin content in Arabidopsis confers improved drought stress resistance. Plant Physiol. Biochem. 82, 209-217. doi: 10.1016/j.plaphy.2014.06.008

Shkolnik-Inbar, D., and Bar-Zvi, D. (2010). ABI4 mediates abscisic acid and cytokinin inhibition of lateral root formation by reducing polar auxin transport in Arabidopsis. Plant Cell 22, 3560-3573. doi: 10.1105/tpc.110.074641

Signora, L., De Smet, I., Foyer, C. H., and Zhang, H. (2001). ABA plays a central role in mediating the regulatory effects of nitrate on root branching in Arabidopsis. Plant J. 28, 655-662. doi: 10.1046/j.1365-313x.2001.01185.x

Skirycz, A., and Inzé, D. (2010). More from less: plant growth under limited water. Curr. Opin. Biotechnol. 21, 197-203. doi: 10.1016/j.copbio.2010. 03.002

Söderman, E. M., Brocard, I. M., Lynch, T. J., and Finkelstein, R. R. (2000). Regulation and function of the Arabidopsis ABA-INSENSITIVE4 gene in seed and abscisic acid response signaling networks. Plant Physiol. 124, 1752-1765. doi: 10.1104/pp.124.4.1752

Stone, S. L., Williams, L. A., Farmer, L. M., Vierstra, R. D., and Callis, J. (2006), KEEP ON GOING, a RING E3 ligase essential for Arabidopsis growth and development, is involved in abscisic acid signaling. Plant Cell 18, 3415-3428. doi: $10.1105 /$ tpc. 106.046532

Su, M., Huang, G., Zhang, Q., Wang, X., Li, C., Tao, Y., et al. (2016). The LEA protein, ABR, is regulated by ABI5 and involved in dark-induced leaf senescence in Arabidopsis thaliana. Plant Sci. 247, 93-103. doi: 10.1016/j. plantsci.2016.03.009

Suhita, D., Kolla, V. A., Vavasseur, A., and Raghavendra, A. S. (2003). Different signaling pathways involved during the suppression of stomatal opening by methyl jasmonate or abscisic acid. Plant Sci. 164, 481-488. doi: 10.1016/S01689452(02)00432-6

Sun, T. P. (2011). The molecular mechanism and evolution of the GA-GID1DELLA signaling module in plants. Curr. Biol. 21, R338-R345. doi: 10.1016/ j.cub.2011.02.036

Sun, X. C., Gao, Y. F., Zhang, N., Li, H. R., Yang, S. Z., and Liu, Y. S. (2015). SISOM inhibits seed germination by regulating the expression of ABA/GA metabolic genes and SIABI5 in Solanum lycopersicum. J. Integr. Agr. 14, 326-336. doi: 10.1016/S2095-3119(14)60859-5

Sun, Y., Fan, X. Y., Cao, D. M., Tang, W., He, K., Zhu, J. Y., et al. (2010). Integration of brassinosteroid signal transduction with the transcription network for plant growth regulation in Arabidopsis. Dev. Cell 19, 765-777. doi: 10.1016/j.devcel. 2010.10.010

Tanaka, Y., Sano, T., Tamaoki, M., Nakajima, N., Kondo, N., and Hasezawa, S. (2006). Cytokinin and auxin inhibit abscisic acid-induced stomatal closure by enhancing ethylene production in Arabidopsis. J. Exp. Bot. 57, 2259-2266. doi: $10.1093 / \mathrm{jxb} / \mathrm{erj} 193$

Tyler, L., Thomas, S. G., Hu, J., Dill, A., Alonso, J. M., Ecker, J. R., et al. (2004). DELLA proteins and gibberellin-regulated seed germination and floral development in Arabidopsis. Plant Physiol. 135, 1008-1019. doi: 10.1104/pp. 104.039578

Wang, C., Yang, A., Yin, H., and Zhang, J. (2008). Influence of water stress on endogenous hormone contents and cell damage of maize seedlings. J. Integr. Plant Biol. 50, 427-434. doi: 10.1111/j.1774-7909.2008.00638.x

Wang, M., Yuan, F., Hao, H., Zhang, Y., Zhao, H., Guo, A., et al. (2013). BolOST1, an ortholog of open stomata 1 with alternative splicing products in Brassica oleracea, positively modulates drought responses in plants. Biochem. Biophys. Res. Commun. 442, 214-220. doi: 10.1016/j.bbrc.2013.11.032

Wang, P., Du, Y., Hou, Y. J., Zhao, Y., Hsu, C. C., Yuan, F., et al. (2015). Nitric oxide negatively regulates abscisic acid signaling in guard cells by S-nitrosylation of OST1. Proc. Natl. Acad. Sci. U.S.A. 112, 613-618. doi: 10.1073/pnas.14234 81112

Wang, Y., Li, L., Ye, T., Lu, Y., Chen, X., and Wu, Y. (2013). The inhibitory effect of ABA on floral transition is mediated by ABI5 in Arabidopsis. J. Exp. Bot. 64, 675-684. doi: 10.1093/jxb/ers361

Wang, Y., Li, L., Ye, T., Zhao, S., Liu, Z., Feng, Y. Q., et al. (2011). Cytokinin antagonizes ABA suppression to seed germination of Arabidopsis by downregulating ABI5 expression. Plant J. 68, 249-261. doi: 10.1111/j.1365313X.2011.04683.x

Won, C., Shen, X., Mashiguchi, K., Zheng, Z., Dai, X., Cheng, Y., et al. (2011). Conversion of tryptophan to indole-3-acetic acid by TRYPTOPHAN AMINOTRANSFERASES OF ARABIDOPSIS and YUCCAs in Arabidopsis. Proc. Natl. Acad. Sci. U.S.A. 108, 18518-18523. doi: 10.1073/pnas.1108 436108

Xi, W., Liu, C., Hou, X., and Yu, H. (2010). MOTHER OF FT AND TFL1 regulates seed germination through a negative feedback loop modulating ABA signaling in Arabidopsis. Plant Cell 22, 1733-1748. doi: 10.1105/tpc.109.07 3072

Yan, F., Deng, W., Wang, X., Yang, C., and Li, Z. (2012). Maize (Zea mays L.) homologue of ABA-INSENSITIVE (ABI) 5 gene plays a negative regulatory role in abiotic stresses response. Plant Growth Regul. 68, 383-393. doi: 10.1007/ s10725-012-9727-x

Yang, X., Bai, Y., Shang, J., Xin, R., and Tang, W. (2016). The antagonistic regulation of abscisic acid-inhibited root growth by brassinosteroids is partially mediated via direct suppression of ABSCISIC ACID INSENSITIVE 5 expression by BRASSINAZOLE RESISTANT 1. Plant Cell Environ. 39, 1994-2003. doi: 10. $1111 /$ pce. 12763

Yang, X. G., Liang, W. H., Li, F., and Ma, W. S. (2012). OsGSK3 is a novel GSK3/shaggy-like gene from Oryza sativa L., involved in abiotic stress signaling. Pak. J. Bot. 44, 1491-1496. 
Yoshida, T., Fujita, Y., Sayama, H., Kidokoro, S., Maruyama, K., Mizoi, J., et al. (2010). AREB1, AREB2, and ABF3 are master transcription factors that cooperatively regulate ABRE-dependent ABA signaling involved in drought stress tolerance and require ABA for full activation. Plant J. 61, 672-685. doi: 10.1111/j.1365-313X.2009.04092.x

Yoshida, T., Mogami, J., and Yamaguchi-Shinozaki, K. (2014). ABA-dependent and ABA-independent signaling in response to osmotic stress in plants. Curr. Opin. Plant Biol. 21, 133-139. doi: 10.1016/j.pbi.2014.07.009

Yu, X., Li, L., Zola, J., Aluru, M., Ye, H., Foudree, A., et al. (2011). A brassinosteroid transcriptional network revealed by genome-wide identification of BESI target genes in Arabidopsis thaliana. Plant J. 65, 634-646. doi: 10.1111/j.1365-313X. 2010.04449.x

Yuan, K., Rashotte, A. M., and Wysocka-Diller, J. W. (2011). ABA and GA signaling pathways interact and regulate seed germination and seedling development under salt stress. Acta Physiol. Plant. 33, 261-271. doi: 10.1007/s11738-0100542-6

Yuan, T. T., Xu, H. H., Zhang, K. X., Guo, T. T., and Lu, Y. T. (2014). Glucose inhibits root meristem growth via ABA INSENSITIVE 5, which represses PIN1 accumulation and auxin activity in Arabidopsis. Plant Cell Environ. 37, 1338-1350. doi: 10.1111/pce.12233

Zhao, W., Guan, C., Feng, J., Liang, Y., Zhan, N., Zuo, J., et al. (2015). The Arabidopsis CROWDED NUCLEI genes regulate seed germination by modulating degradation of ABI5 protein. J. Integr. Plant Biol. 58, 669-678. doi: $10.1111 /$ jipb. 12448

Zhao, Y., Xing, L., Wang, X., Hou, Y. J., Gao, J., Wang, P., et al. (2014). The ABA receptor PYL8 promotes lateral root growth by enhancing MYB77dependent transcription of auxin-responsive genes. Sci. Signal. 7:ra53. doi: 10. 1126/scisignal.2005051

Zhong, C., Xu, H., Ye, S., Wang, S., Li, L., Zhang, S., et al. (2015). AtGASA6 serves as an integrator of gibberellin-, abscisic acid-and glucose-signaling during seed germination in Arabidopsis. Plant Physiol. 169, 2288-2303. doi: 10.1104/pp.15. 00858
Zhou, X., Hao, H., Zhang, Y., Bai, Y., Zhu, W., Qin, Y., et al. (2015). SOS2like protein kinase5, an SNF1-related protein kinase3-type protein kinase, is important for abscisic acid responses in Arabidopsis through phosphorylation of ABSCISIC ACID-INSENSITIVE5. Plant Physiol. 168, 659-676. doi: 10.1104/ pp.114.255455

Zhou, X., Yuan, F., Wang, M., Guo, A., Zhang, Y., and Xie, C. G. (2013). Molecular characterization of an ABA insensitive 5 orthologue in Brassica oleracea. Biochem Biophys. Res. Commun. 430, 1140-1146. doi: 10.1016/j.bbrc. 2012.12.023

Zinsmeister, J., Lalanne, D., Terrasson, E., Chatelain, E., Vandecasteele, C., Vu, B., et al. (2016). ABI5 is a regulator of seed maturation and longevity in legumes. Plant Cell. doi: 10.1105/tpc.16.00470

Zou, M., Guan, Y., Ren, H., Zhang, F., and Chen, F. (2007). Characterization of alternative splicing products of bZIP transcription factors OsABI5. Biochem. Biophys. Res. Commun. 360, 307-313. doi: 10.1016/j.bbrc.2007.05.226

Zou, M., Guan, Y., Ren, H., Zhang, F., and Chen, F. (2008). A bZIP transcription factor, OsABI5, is involved in rice fertility and stress tolerance. Plant Mol. Biol. 66, 675-683. doi: 10.1007/s11103-008-9298-4

Zwack, P. J., and Rashotte, A. M. (2015). Interactions between cytokinin signalling and abiotic stress responses. J. Exp. Bot. 66, 4863-4871. doi: 10.1093/jxb/ erv172

Conflict of Interest Statement: The authors declare that the research was conducted in the absence of any commercial or financial relationships that could be construed as a potential conflict of interest.

Copyright (c) 2016 Skubacz, Daszkowska-Golec and Szarejko. This is an open-access article distributed under the terms of the Creative Commons Attribution License (CC BY). The use, distribution or reproduction in other forums is permitted, provided the original author(s) or licensor are credited and that the original publication in this journal is cited, in accordance with accepted academic practice. No use, distribution or reproduction is permitted which does not comply with these terms. 